\title{
Resource Criticality in Modern Economies: Agent-Based Model Demonstrates Vulnerabilities from Technological Interdependence
}

\author{
John Sherwood ${ }^{1}$ (1) $\cdot$ Anthony Ditta $^{2} \cdot$ Becky Haney $^{3} \cdot$ Loren Haarsma $^{4} \cdot$ \\ Michael Carbajales-Dale ${ }^{1}$
}

Received: 7 February 2017 / Accepted: 7 June 2017 / Published online: 17 June 2017

(c) The Author(s) 2017. This article is an open access publication

\begin{abstract}
Industrialized society will transition away from dependence on non-renewable resources (fossil fuels, in particular) sometime in the foreseeable future. How disruptive this transition will be to the economy and societal well-being is unknown, particularly if there are any sudden resource supply constraints. However, the effects of resource supply constraints on an economy, or models of the interdependent relationship between the economy and natural capital overall have not been thoroughly developed. One problem is that traditional models of the economy assume linear growth, while highly interdependent industrialized economies may behave more like a complex adaptive system with non-linear, path-dependent, and unexpected growth trajectories. Agent-based models have been shown to successfully model important aspects of a complex adaptive economy. This paper uses an agent-based model to demonstrate potential economic impacts for industrialized economies in the face of a sudden resource supply constraint. Economic "agents" mine resources and invent technology. Through trade and specialization, the economy evolves from a collection of self-sustaining, resource-poor agents to a society with a high degree of interdependence and wealth. Economic growth, however, comes with a cost;
\end{abstract}

John Sherwood

jgsherw@clemson.edu

1 Department of Environmental Engineering and Earth Sciences, Clemson University, Clemson, SC, USA

2 University of Chicago Booth School of Business, Chicago, IL, USA

3 Department of Economics, Calvin College, Grand Rapids, MI, USA

4 Department of Physics, Calvin College, Grand Rapids, MI, USA the interdependence that arises from specialization and trade also leads to a less resilient economy. Unexpected, large economic collapse can arise from a shock to even a single resource, due to each resource's interdependent role in the economy.

Keywords Agent-based model · Resource criticality · Technological evolution $\cdot$ Evolutionary complexity . Biophysical economics

\section{Introduction and Background}

\section{Resource Depletion and Criticality Concerns}

Despite a strong historical record of societies facing resource supply constraints, relatively little analysis of the relationship between exhaustible or constrained resources and the economy appears in the mainstream economics literature. Notable exceptions include Hotelling (1931), Hartwick (1977), (Hartwick 1978), and Nordhaus (1979). However, their models do not place natural resources as the driver of economic activity. Instead, pricing systems and well-functioning markets insulate the economy from resource constraints.

Conversely, an economy's dependence on natural resources is the center piece of an interdisciplinary, biophysical approach to economics. This approach goes beyond environmental economics, which simply examines the markets and market failures related to natural resources. Instead, the biophysical approach starts with ecology and understands the economy as "a wholly owned subsidiary of the ecosystem," as economist Herman Daly has been often quoted as saying (Daly 2005). Seeing the economy as a system wholly dependent on and ultimately tied to the 
Fig. 1 Cuba historical GDP per capita and energy imports per capita. Data from The World Bank (2017)

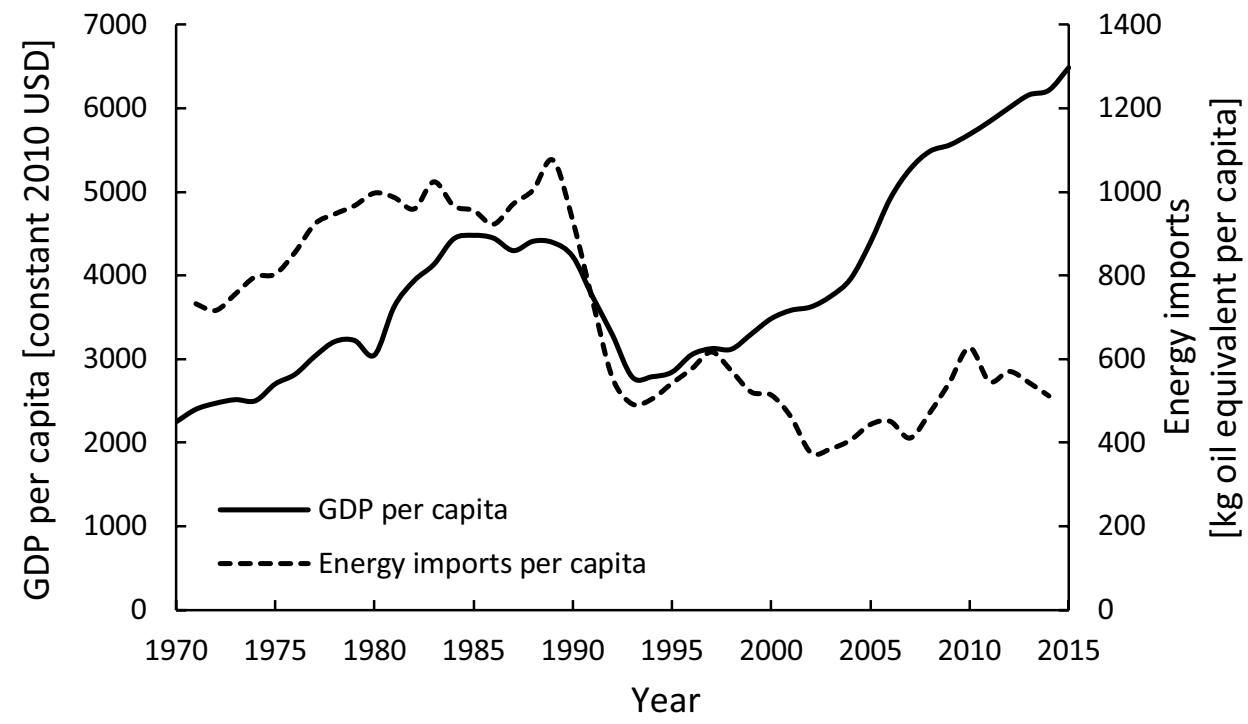

health of a larger natural system brings questions related to sustainability to the fore rather than as an afterthought, and particularly after a crisis.

Near-complete socioeconomic collapse appears to have occurred several times in history due to natural resource (mis)management. Examples include the inhabitants of Easter Island, and the Minoan, Mayan, and Anasazi societies, although there is not full agreement on the exact causes of collapse (Tainter 1990; Tainter 2006). Conversely, in more recent and recorded history, predictions of imminent collapse due to natural resource supply constraints have rarely materialized and most industrialized societies have weathered a variety of transitions through innovation. Yet, collapse is not outside the realm of possibility. Cuba experienced a severe collapse in GDP when it lost access to a significant portion of its energy imports upon the dissolution of the Soviet Union in 1989, as seen by the large drop in the dashed line in Fig. 1. In large part due to this constrained supply of energy resources, Cuba soon experienced a $35 \%$ drop in GDP. The Cuban electric grid experienced severe supply disruptions which, along with the loss of imports from the Soviet Union, contributed to significantly reduced economic output. Cuba faced starvation and potential societal collapse during what Cubans call the "Special Period." Strong communities, social cohesion, and policy measures gradually transitioned Cuban society to a new normal (Piercy et al. 2010; Friedrichs 2010). Cuba's industrial output recovered eventually, despite energy imports remaining low. This advanced economy experienced first-hand the potential effects of a natural resource supply constraint: a severe collapse and painful, slow but eventual recovery.

Though Cuba adapted, the fact that the country needed drastic measures highlights how dependent modern-day society is on a supply of natural resources, and that a constrained supply may prompt drastic shifts throughout an economy. Additionally, the chances of encountering a supply constraint can increase as more people desire and consume more resources, particularly if resource acquisition technology fails to keep pace with demand. Vaclav Smil has stated that, as the world population continues to grow, the absolute rate of resource consumption will increaseeven while accounting for diminishing per capita resource consumption in OECD countries (Smil 2013). ${ }^{1}$

Furthermore, globalization continues to forge economic connections across continents-most economies were affected by the 2008 U.S. housing crisis and subsequent recession (Claessens et al. 2010). Therefore, if a supply constraint is encountered, it will likely affect the entire world economy.

\section{Where are Resources in Macroeconomic Growth Models?}

Despite the potential for painful, global economic collapse due to natural resource constraints, economic implications of resource constraints as a research topic receive relatively little attention. One reason for this is that macroeconomic models rely on assumptions that downplay or eliminate the role of natural resources. The predominant models used to examine economic output fall into two general categories: (1) aggregate growth accounting models, such as the Solow growth model, and (2) computational general equilibrium

\footnotetext{
1 Theoretically, it is possible to have a decline in total material consumption at the same time as population growth. This would occur if the rate of population growth is less than the rate of dematerialization per capita. However, as Smil points out in (Smil 2013), this has not been observed empirically and is unlikely to happen.
} 
models, such as dynamic stochastic general equilibrium (DSGE) heavily used by the Federal Reserve for economic and policy analysis (Del Negro 2013). These two categories of approaches exist because they make different assumptions about the structure underlying the dynamics of macroeconomic aggregate measures. However, both approaches have been heavily criticized for failing to account for biophysical reality and failing to acknowledge binding biophysical constraints on economic growth (Kümmel et al. 1985; Hall et al. 2001; Hoel and Kverndokk 1996; Hirsch 2005). The failure of both approaches to account for the relationship of the environment and the economy can be traced to four problematic assumptions regarding resources:

Assumption 1 (Factor Substitution) Most economic models assume natural resources and built capital are substitutable inputs into production. Resource scarcity is not a significant concern long-term because price signals will guide economic actors away from increasingly scarce natural resources and toward innovations to replace them. However, the work of Graedel and others on resource criticality indicates that several materials have limited to no substitutability, effectively "decoupling materials substitution from price signals" (Graedel et al. 2015a, b). Furthermore, technological advances often use increasingly unique and varied material requirements to improve designs. Some economists, such as Stern, have begun to recognize the limits of substitution when the economy is viewed as a complex adaptive system (Stern 1997).

Assumption 2 (Cost-share Theorem) The Solow growth model and certain extensions that include materials and/ or energy assume that factors of production influence economic growth based on their overall cost-share (Gullickson and Harper 1987; Ayres and Warr 2005). Because the costshare of energy and raw materials are relatively low, the implicit assumption is that a resource supply constraint will have a minimal effect on the overall economy. Ayres et al. argue that resources like energy are much more important than their cost-share, such that a small drop in supply will have drastic effects on the overall economy (Ayres et al. 2013). The authors state that cost-shares undervalue resources because cost is only related to extraction and not the intrinsic value of a resource (Ayres et al. 2013).

Assumption 3 (Perfect Knowledge and Foresight) In economic models of resource allocation, such as in the Hotelling or Ricardian models, it is assumed that the resource allocators accurately know the level of resource scarcity (Hotelling 1931). However, Norgaard criticizes this (Norgaard 1990). The theoretical models require perfect information about resource deposits, while much empirical work implicitly assumes that at least the resource allocators have perfect information regarding their deposits. Neither the theoretical or empirical approach correlate particularly well with history. Norgaard comments that economists' "theoretical models do not readily explain economic history with respect to the most basic patterns and hence are not likely to be useful..." to understand resource scarcity (Norgaard 1990).

Assumption 4 (Representative Agents) General equilibrium models attempt to link macroeconomic output to the underlying behavior of a few, representative agents. Each agent stands in for a multitude of heterogeneous economic agents. Deep interdependencies that result from specialization and path-dependent trade networks cannot be captured in even the most advanced representative agent model (Del Negro 2013). The failure of representative agent models to predict the massive global collapse in the international banking system reveals the severity of this limitation (Squazzoni 2010). Resource supply constraints can cause cascading collapse similar to that of the global financial crash due to the interconnectedness of technologies and agents.

This paper claims that to understand how a seemingly wealthy, advanced economy could experience an unexpectedly severe collapse and possible recovery scenario, a model cannot be limited by any of the above four assumptions. A growing body of diverse research, predominantly outside the mainstream of economics, has been able to relax at least one, but not all of these assumptions. Significant examples include:

Assumption 1 Mainstream economists such as Hotelling, Hartwick, and Nordhaus have developed theoretical models of natural resource depletion and economic growth when factor substitution is limited (Hotelling 1931; Hartwick 1977, 1978; Nordhaus 1979). More recently, Smulders et al., and Brock and Taylor have attempted to extend computable general equilibrium models to include interactions with the environment (Smulders et al. 2014; Brock and Taylor 2005).

Assumption 2 A robust interdisciplinary literature exists that ignores the cost-share assumption and adds energy as a primary input factor to growth accounting models, including the work of Ayers and Warr (2013), Kümmel et al. (1985), and more recently Heun et al. (2017).

Assumption 3 Systems dynamics models have examined the effect of resource depletion on the macroeconomy when economic agents do not have perfect foresight, or do-but are limited in their ability to act on it, including meadows 
and randers' World3 model, used in Limits to Growth, and Nordhaus' (1993) DICE integrated assessment model (Meadows et al. 2004).

Assumption 4 Agent-based models (ABM) of the economy are designed specifically to alleviate the need for representative agents. A growing body of research that uses ABM to study the economy exists. However, Balint et al. (2017) provide a recent, comprehensive review of environmental macroeconomic models and identifies few, if any, ABM that also include resource dependency and technological innovation in their framework.

None of these models, however, use a resource-dependent economic framework and explicitly model the relationship between technological innovation, technological interdependency, resource criticality, and the dynamics of macroeconomic outcomes. The primary contribution of this paper is to demonstrate that underlying technological interdependencies, emerging over time from trade networks of heterogeneous economic agents, can lead to both exponential growth in output and increasing resource criticality.

\section{Why Use Agent-Based Models to Understand Resource Criticality?}

The model developed in this paper belongs to a growing class of agent-based models (Balint et al. 2017) used to examine how economic agents interact and develop trade networks. In our case, agents also interact with their natural environment and develop technology. The agents' underlying economic decisions form trade networks, capital infrastructure, and draw down natural resources. Macroeconomic aggregate outcomes emerge as an explicit result of economic behavior. As an economy grows increasingly interdependent from these interactions, it has been shown to behave as a complex adaptive system (Andersen 1996; Anderson and Arrow 1988; Arthur et al. 1997; Durlauf 2012; Kirman 2016; Colander and Kupers 2014). Agentbased models are a particularly appropriate methodology for examining an economy as a complex adaptive system.

Interdependence can be simulated through an agentbased model, a relatively new modeling technique based on defining rules for individual agent behavior. Agents' interactions with each other and the macroeconomy that they create generate macroeconomic time series that can trace out trajectories similar to those that result from Solow growth models or dynamic stochastic general equilibrium models (Tesfatsion and Judd 2006). Agent-based models (ABM) provide a 'laboratory' to model the outcomes of alternative policies, behavioral assumptions and social norms (Holland and Miller 1991). For example, Epstein and Axtell's Sugarscape ABM can replicate neoclassical comparative statics models of commodity trade price equilibrium. The initial conditions of the model can be set to mimic the neoclassical behavioral assumptions of agents (full information, rational, self-interested) and show that such an economy left to its own devices can lead to a "socially optimal" outcome where commodity trade prices reflect actual utility of the commodities. That is, they can reproduce the evidence that is used to make the case for laissez-faire economic policies. However, they also generate several counterfactuals by making the agents "progressively less neoclassical" such as having culturally conditioned preferences, and show that under different assumptions, laissez-faire policies can lead to less efficient outcomes accompanied by greater inequality (Epstein and Axtell 1996).

A number of ABMs 'grow' economies "from the bottom up" and model bi-lateral exchanges between agents in ways that are useful to examine the dynamic and complex nature of the modern economy (Epstein and Axtell 1996; Hamill and Gilbert 2016). While all of them model certain aspects of the modern economy, none of them explicitly model the deep level of technological interdependence that has emerged since the industrial revolution. Thus, while previous models are complex adaptive systems, they do not include the interdependence arising from invention of technology.

The model presented here is called self-organizing complex interdependent evolving technology in an economic system, or SOCIETIES. ${ }^{2}$ It is one of the first ABM that directly simulates resource-dependent technological innovation and capital formation in order to study the interdependence found within the economy. By building a virtual resource-dependent economy from the bottom up, we study both the increased economic production and vulnerability to collapse and recovery that come with resource criticality. Because the simulation explicitly models resource and technological development pathways, it can provide much needed insight into the effect of resource supply constraints on technologically advanced economies.

\section{Model Description}

\section{Overview}

SOCIETIES is based on four basic elements: agents, resources, devices, and trade. Agents represent firms, communities, or regions who increase their utility by extracting

\footnotetext{
2 The software is available as open source under the GPL license and is available for download and extension by the research community at https://github.com/bhaney22/SocietiesABM.
} 


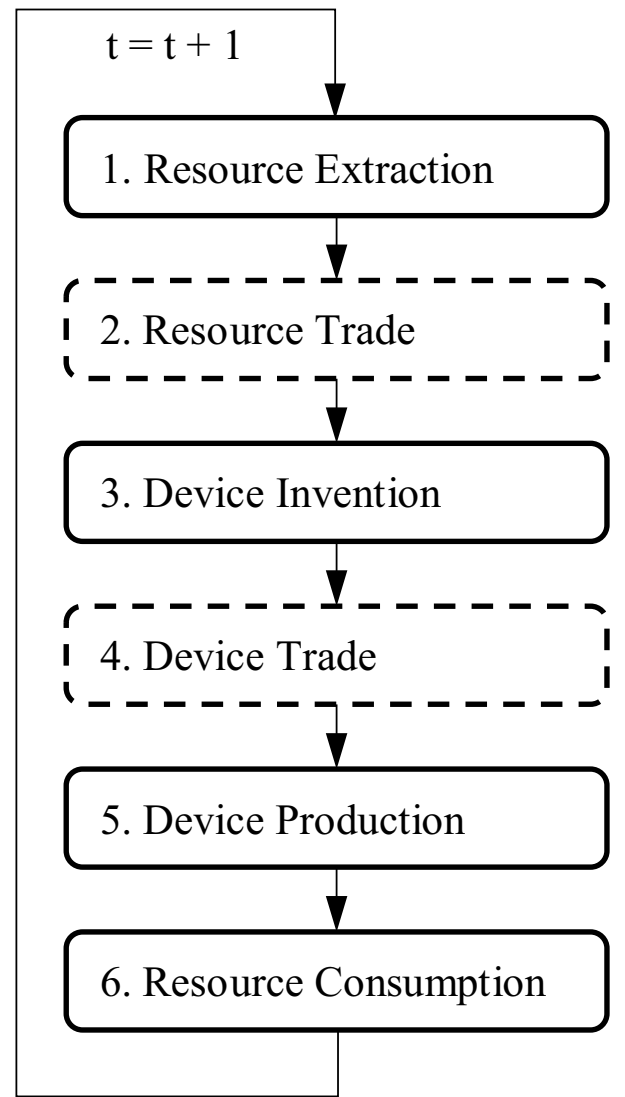

Fig. 2 Overview of agent phases per time-step. Dashed boxes represent social interaction phases

resources. Agents can construct devices that speed up resource extraction and thus increase utility gains, however the devices require resources to build. The agents gain experience extracting specific resources or building devices, which increases the efficiency of those tasks. This allows for specialization and creates incentives to trade. The agents can trade resources or devices with one another through random bi-lateral trade pairings that occur once per time-step.

All agents start out homogenous, and only begin to differentiate themselves through stochastic choices. The initial homogeneity of agents guards against specifying particular producers or consumers for a certain device or resource. Any resource criticality due to trading relationships will emerge from the nature of the model. Additionally, all resources are homogenous with identical utility curves (see "Resource Extraction"). This ensures that any sort of resource criticality only emerges through the nature of technology rather than by generating desirability of a resource due to some intrinsic resource property.

\section{A Day in the Life of an Agent}

Agents cycle through six phases each time-step, shown in Fig. 2. All agents progress through the phases in parallel, allowing them to interact during the trade phases (represented by dashed boxes in Fig. 2).

\section{Agents}

Agents are initially homogenous, self-interested, and fully rational economic actors. They cannot die, do not procrastinate, and can switch between tasks with no transaction costs. They perfectly calculate costs and benefits to decide which resource to extract or which device to make based on utility gains. Agents make decisions that optimize their extraction efficiency and thus utility gain each time-step. When trading, they have no strategic or information advantage over each other and barter/trade honestly and only when both parties benefit.

However, their rationality is bounded. The agents have limited memory and only a certain amount of foresight. They do not anticipate gains from trade when deciding which resource to extract. They can only communicate pair-wise during barter. The only information they can use for trading resources is the value they themselves put on each resource. When trading devices, they factor in how efficiently they can use the device based on the previous time-step. They also remember the last few days of trades. Agents are not able to anticipate gains from future trades when calculating the benefit of producing a device; they only consider the benefit it provides them in extracting resources for themselves. 24 agents exist in the current model. This is enough to ensure heterogeneity but also relatively smooth aggregated model outputs. For more information on the number of agents, see the appendices.

\section{Resources}

Resources are homogenous, differentiated only by agents' experience with them. Each resource has a utility curve that reflects its value. Agents consume a constant proportion of each of their resources every time-step. This accounts for resources being used, wearing out, or breaking down over time. 24 resources exist in the current model-enough so that each agent can uniquely specialize if they choose to. The choice of number of resources is also discussed in the appendices.

\section{Resource Extraction}

The SOCIETIES model contains nested time-steps. Each high-level time-step represents every agent progressing through each phase in Fig. 2. For clarity in the model 


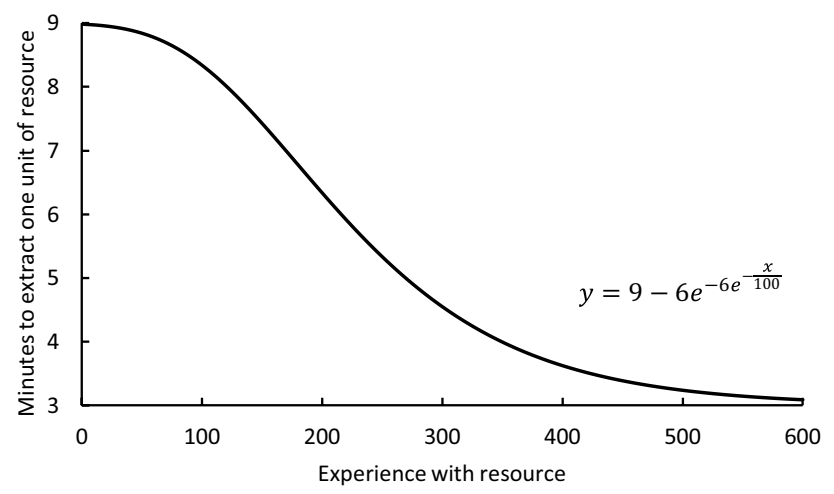

Fig. 3 Resource effort curve

description, we call these global time-steps "days," though they do not represent a day to society on Earth. Within each "day," agents have a fixed number of "minutes" that can be used to extract resources or build devices (see "Device Production"). Extracting a resource takes a number of minutes, dependent on the agent's experience level. An agent gains experience for a specific resource every time the agent extracts it. At higher resource experience levels, it takes fewer minutes to extract a resource. The exact relationship is shown in the resource effort curve as Fig. 3.

The sigmoid represented in Fig. 3 is produced by the Gompertz function (a generalized logistic function) shown to the right of the curve. This is one of many choices of functions that can be employed to model a learning a task. Following (Pan and Köhler 2007), we chose this type of function to model learning-by-doing that results initially in minimal gains for experience, then significant gains from experience, then finally no gains due to physical limitations which cannot be overcome with further experience. It is ideal for the purposes of our model in that it rewards specialization and promotes trade in resources and technology. The parameters that define the particular shape of the sigmoid were chosen so that agents would require several days to reach maximum experience. This allows the economy to change in small increments each time-step, but to change significantly in just a few hundred time-steps.

Each resource could have a different effort curve in principle, though for this paper the curves will be homogenous to limit any inherent resource uniqueness or criticality. The effort curve does, however, provide a reward (experience) for an agent to specialize in a specific resource. But, if an agent does not extract a specific resource during a day, they lose three experience for that resource. This simulates losing unused skills.

Agents decide which resource to extract by the amount of "utility" it provides them. Utility curves are defined as $\mathrm{U}(x)=D x^{1 / n}$, where $D$ is the utility of the first unit; $x$ is

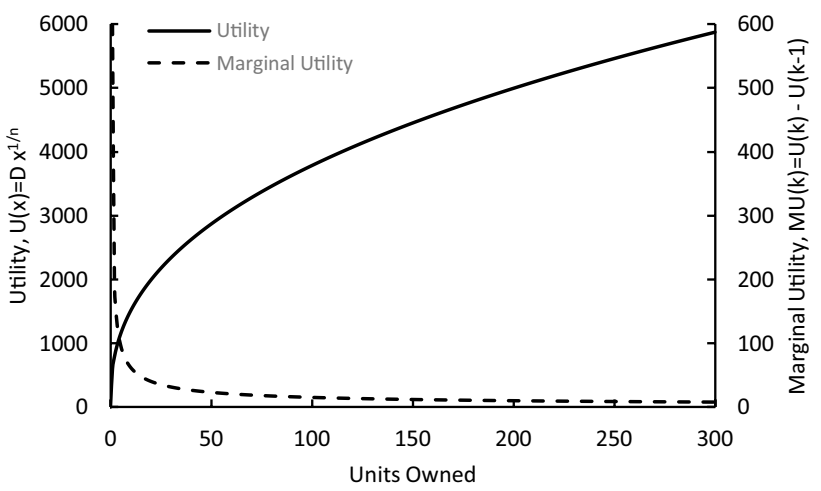

Fig. 4 Utility (left axis) and marginal utility (right axis) as a function of resource units owned by an agent. Here, $D=600$ and $n=2.5$ which were used in all model runs presented

the number of units owned ${ }^{3}$, and $n$ is a control parameter to adjust the curvature, causing diminishing returns, as shown in Fig. 4. Resources are restricted to discrete units, so the marginal utility of the $k^{\text {th }}$ unit is $\mathrm{MU}(k)=\mathrm{U}(k)-\mathrm{U}(k-1)$. The marginal utility of resource $i$ eventually falls below the initial marginal utility of resource $j$, such that all resources are extracted.

Agents choose to extract the resource that provides the most utility gain per minute. If an agent has $x$ units of resource $r$, the utility gain per minute is

Gain per minute $(\mathrm{GPM})=\frac{\mathrm{MU}\left(x_{\mathrm{r}}+1\right)}{e_{\mathrm{r}}}$

where $e_{\mathrm{r}}$ is the effort required to extract resource $\mathrm{r}$, which is further reduced by a factor of $3^{\tau}$ when using devices of tier $\tau$ for resource $r^{4}{ }^{4}$ The agent performs this calculation for each resource before each time (minute) investment. Note that, this is the only decision heuristic for resource extraction; agents do not anticipate future gains from trade when making extraction decisions.

A process diagram for resource extraction is shown in Fig. 5.

\footnotetext{
${ }^{3}$ As such, the utility of a particular resource may increase as an agent's stock of that resource is depleted.

${ }^{4}$ Effort is a function of experience extracting a resource, shown in Fig. 2, and device tier. The equation to calculate effort is

$e_{r}=\frac{9-6 e^{-6 e^{-\frac{x_{r}}{100}}}}{3^{\tau}}$

$x_{\mathrm{r}}$ is the amount experience with resource $\mathrm{r}$ and $\tau$ is the device tier, 1-4. $\tau=0$ when no devices are used to extract a resource.
} 


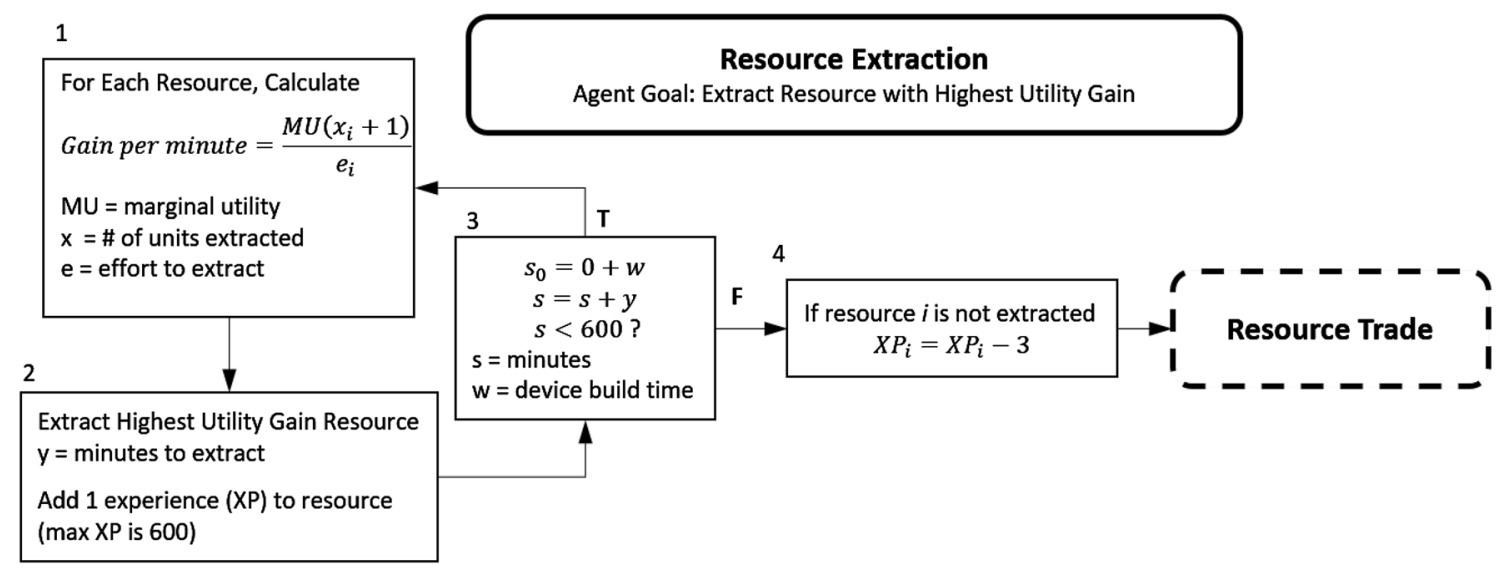

Fig. 5 Resource extraction phase process diagram

Fig. 6 Resource trade phase process diagram
Resource Trade

Agent Goal: Find a Mutually Beneficial Trade

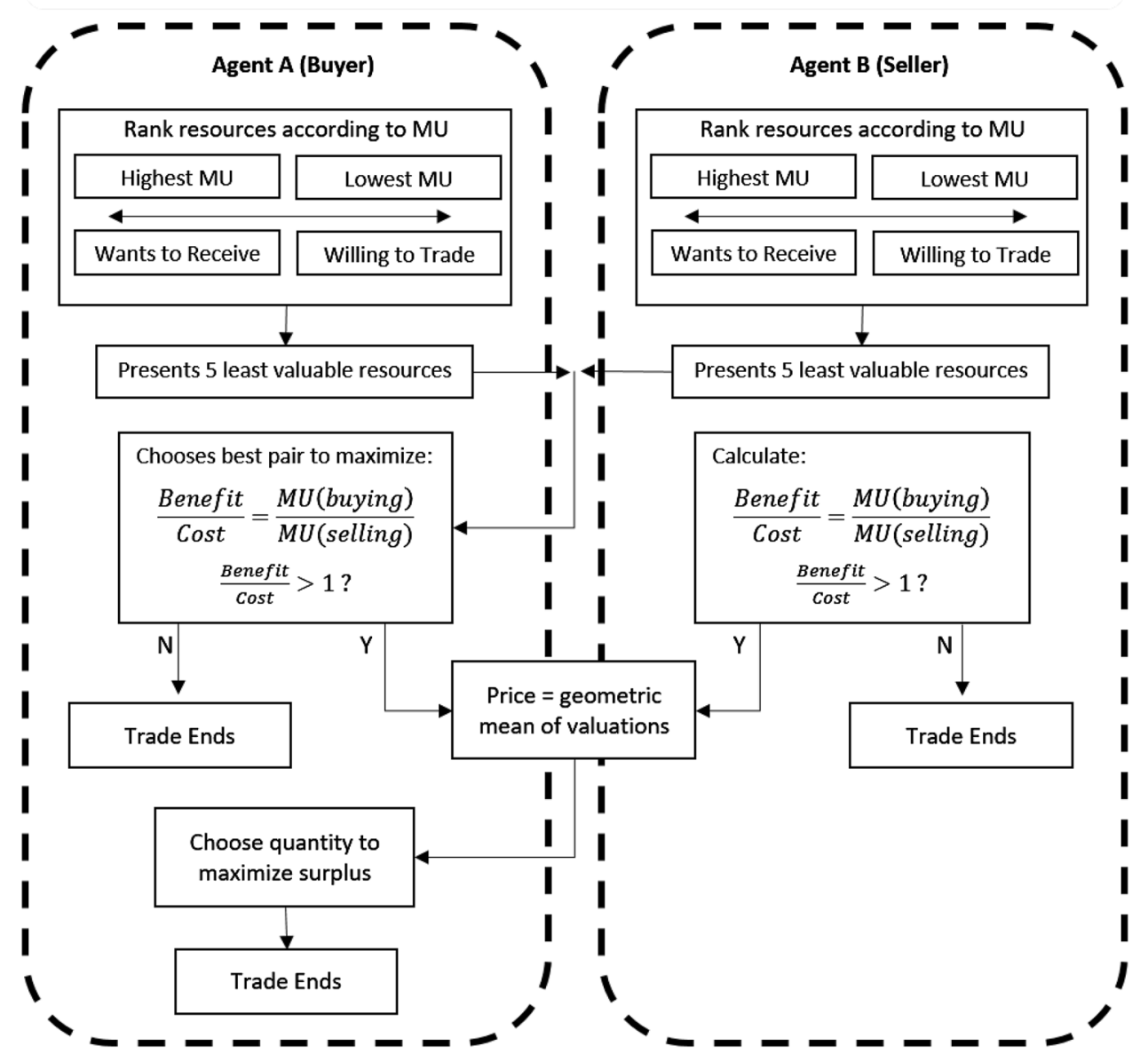

\section{Resource Trade}

Agents pair to trade resources multiple times. For this paper, all agents go through 12 trade rounds. The rounds are simple bi-lateral trades between honest agents; strategic bartering behavior is not explored. The agents follow the process diagram shown in Fig. 6. When agents are randomly paired, each one ranks their resource holdings from most to least valuable based on their MU from the last unit received. Note that, agents only look back at previous MU 


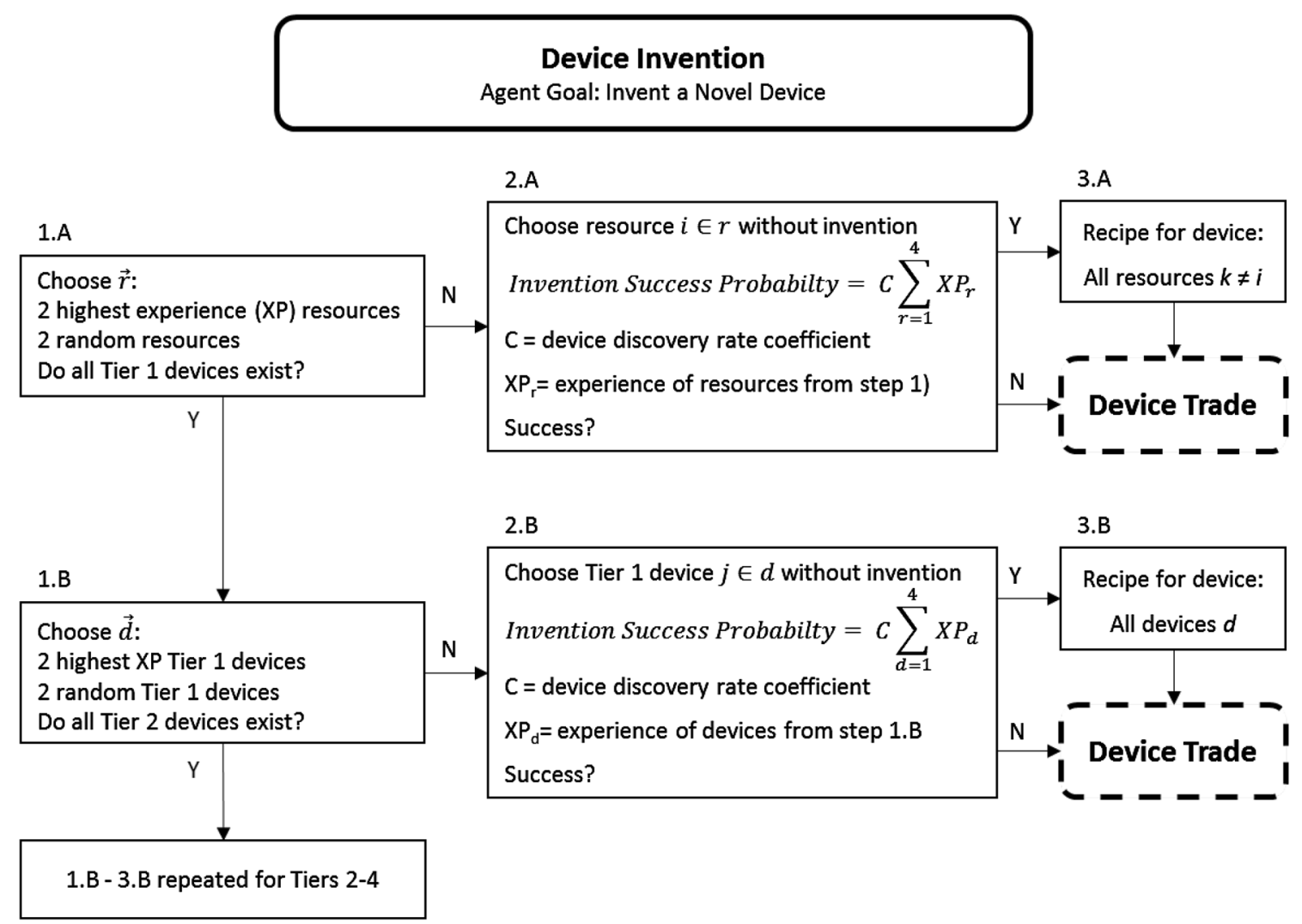

Fig. 7 Device invention phase process diagram

when calculating gains from trade; they do not account for future resource extraction. The agent may benefit by trading low MU resources for high MU resources. If there is a net utility gain, defined by $\sum^{M} U$ (buying) $-\sum^{M} U$ (selling), then an agent will agree to trade.

When agents are paired, they offer to trade their five least valuable resources. One agent is randomly assigned as the "buyer" or decision-maker (agent $\boldsymbol{A}$ ). Agent $\boldsymbol{A}$ chooses a pair of resources to maximize its net utility gain. Agent $\boldsymbol{B}$, the "seller," calculates its net utility for the chosen pair. If both $\boldsymbol{A}$ and $\boldsymbol{B}$ benefit from the potential trade, a price is determined as the integer rounded geometric mean of the agents' valuations, following Epstein and Axtell (1996).

Next, $\boldsymbol{A}$ chooses the quantity to trade that maximizes its net utility gain. $\boldsymbol{B}$ accepts if $\boldsymbol{B}$ still gains from the trade. If $\boldsymbol{B}$ does not gain from the offered quantity, $\boldsymbol{B}$ make a counter-offer using its maximizing quantity. $\boldsymbol{A}$ either accepts the counter-offer, or restarts the trade round with switched roles ( $\boldsymbol{A}$ will try being the "seller"). Regardless of completing a trade, the two agents swap roles five times before the round of trading ends. Once all trade rounds are complete within the resource trading phase, agents advance to the device invention phase.

\section{Devices}

Devices are inventions that speed the extraction of resources. Initially, agents have no devices. As agents gain experience with resources, they become increasingly likely to invent a device for that resource because they learn how to extract it better. The first devices invented are simple, made from a combination of resources. As agents gain experience with simple devices, they begin to invent more complex devices by combining lower-level devices, each level offering more efficient resource extraction. Each device has a finite lifetime and wears out more quickly through use.

\section{Device Invention}

Once resource trading ends, agents have an opportunity to invent a device. Tier 1 devices are invented by combining four resources: two random and the two highest experience resources for the agent. If a tier 1 device has already been invented for all four resources, the agent attempts to invent a tier 2 device by combining four tier 1 devices. The probability of successfully inventing a device is proportional to the sum of experience from all underlying components, and is always less than one. 
Fig. 8 Example recipe tree for a tier 4 device. The tier 4 device for resource four is highlighted, along with its direct dependencies. While only 12 resources (and subsequent devices) are shown, the model contains 24 resources. In this example only resources $1-12$ are used to build tier 4 device four, though numerous combinations are possible (including dependencies on resources 12-24)

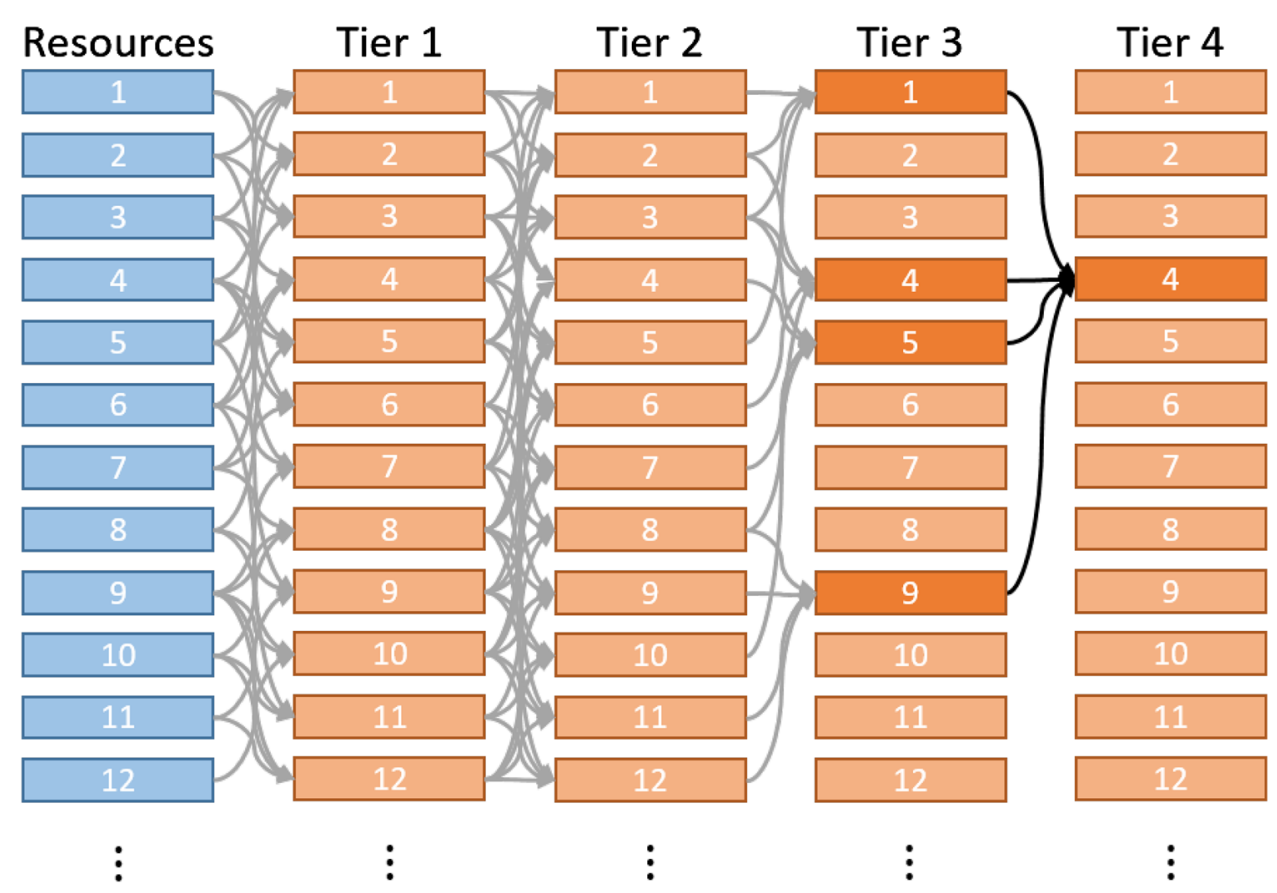

When a device is invented, the combination of components is considered that device's formula or recipe. Every device of the same type will follow that recipe-other agents learn the recipe by purchasing the device from the inventor. This behavior allows for a certain "patent" length on a device type and creates a diffusion of technology within the society. See Fig. 7 for the process diagram of device invention, and Fig. 8 for an example device recipe tree for a tier 4 device.

Devices reduce the effort required to extract a resource (by a factor of $3^{\tau}$, where $\tau$ is the device tier) but have a finite lifetime and wear out through use. The lifetime is measured in minutes used during the resource extraction phase. Devices have a lifetime of $150,300,600$, and $1200 \mathrm{~min}$ for tiers $1-4$, respectively. These lifetimes correspond to $1 / 4,1 / 2,1$, and 2 days. So, higher order devices are both more efficient and more durable. We chose these values to create quick capital changeover while still ensuring a device would be worth the cost of its construction. If device lifetimes were too long, it would take more computing resources for essentially the same result-a shift in the structure of an economy.

\section{Device Trade}

Agents trade devices after the invention phase, so that they can both invent and trade within the same day. Device trade is very similar to resource trade, though with a few differences. "Buyer" agents are randomly selected, but they choose a "seller" from a pool of successful trade partners (if none exist, an agent is randomly selected). We allow this agent memory in order to form device trade networks. A trade network approach is much more successful than relying on random agent pairing because devices are initially scarce and require significant resource inputs. The process flow diagram is shown in Fig. 9.

The pair of agents goes through 12 trade rounds, just as in resource trading. Within a round, the "buyer" (agent $\boldsymbol{A}$ ) calculates its potential benefit from each device the "seller" (agent $\boldsymbol{B}$ ) can produce ${ }^{5}$. The potential benefit is measured in utility gained by using the device compared to not using it:

Benefit $=[\mathrm{U}(z)-\mathrm{U}(x)]-[\mathrm{U}(y)-\mathrm{U}(x)]$

Here, $z$ is the final amount of a resource after using the device if purchased, $x$ is the starting amount of a resource (after any currently held devices are used up), and $y$ is the final amount of a resource if it were extracted using the same amount of minutes without the device. Agent $\boldsymbol{A}$ then calculates the cost of producing the same device for itself, allowing for a "make-or-buy" decision. If agent $\boldsymbol{A}$ could make the device (production requires device experience, see "Device Production"), the device cost is the sum of component costs plus the opportunity cost of spending minutes to produce it rather than extract something. This

\footnotetext{
5 Devices are made to order. The selling agent does not need inventory for the buyer to place an order, though the seller must spend minutes in the next day to produce the ordered device.
} 
Fig. 9 Device trade process flow diagram

\section{Device Trade}

Agent Goal: Find a Mutually Beneficial Trade

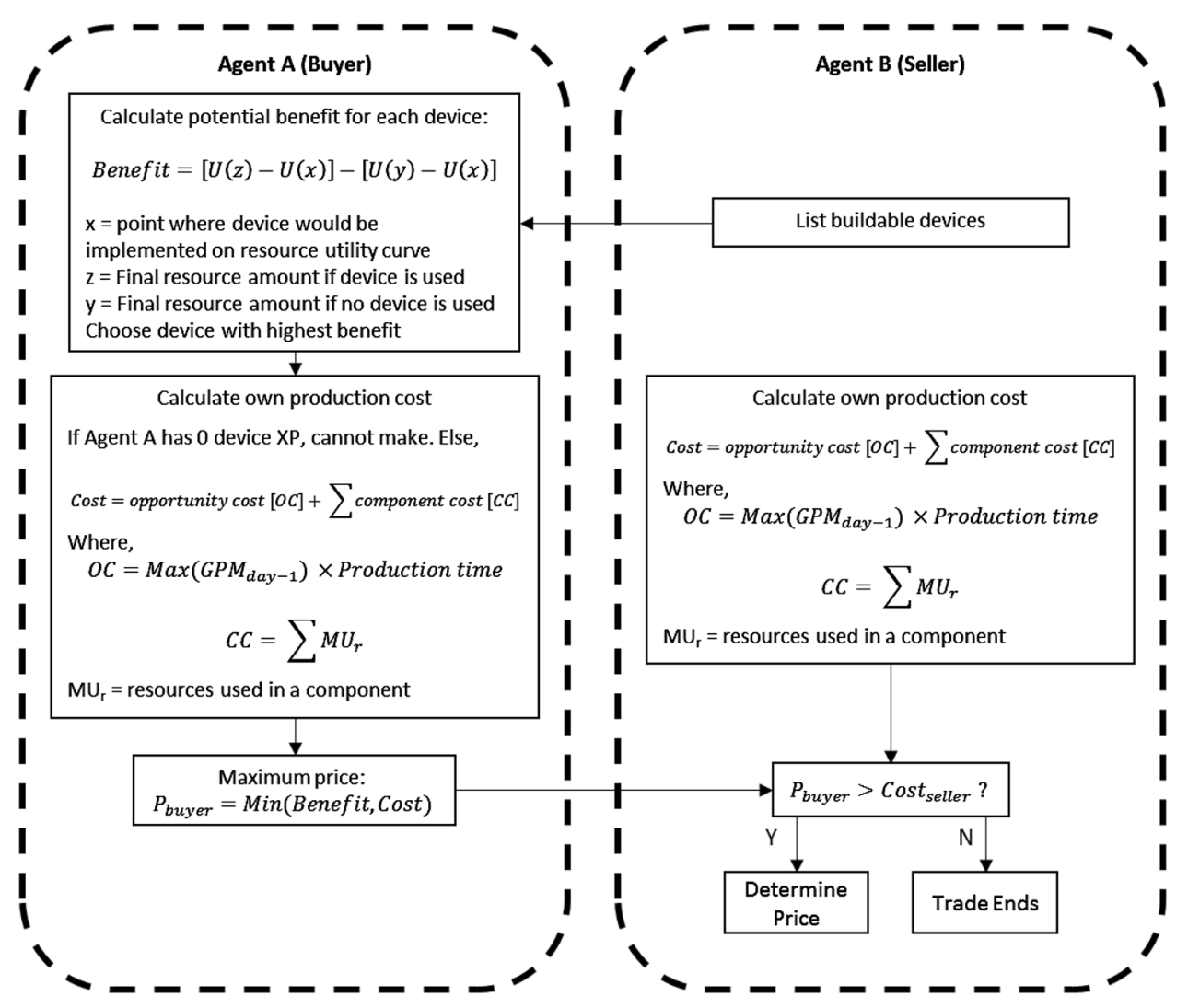

extraction opportunity cost is calculated using the highest final GPM in the previous day.

The component costs are calculated differently for tier 1 and for higher tier devices. Because tier 1 devices are directly built with resources, the cost is the sum of the marginal utility of all resources used to build the tier 1 device. For higher order devices, the cost can be calculated two ways: through direct production or old trade data. The direct production cost is the summed marginal utility of all resources used to build all components that are used to build the device. However, if agent $\boldsymbol{A}$ purchased a component in the past 5 days, it will substitute the purchase price for the production cost of that component if the purchase price is lower. For this paper, trade data older than 5 days are forgotten by agents.

Agent $\boldsymbol{A}$ then determines the value of the device, which is the minimum of potential benefit and production cost. If a buyer paid more than the benefit or the production cost, it would lose out on utility. So, this value is the maximum price agent $\boldsymbol{A}$ is willing to pay. Agent $\boldsymbol{B}$ also determines its valuation of the device, which is equal to $\boldsymbol{B}$ 's production cost. For a trade to occur, $\boldsymbol{B}$ 's value must be less than $\boldsymbol{A}$ 's value.
The price is determined in a similar way as resource trade, with resources being used as the currency. The device buyer $(\boldsymbol{A})$ offers one unit of a resource it wants to trade away (its least valuable resource) and adds it to a list. Then the seller $(\boldsymbol{B})$ chooses one unit of a resource it wants the most ( $\boldsymbol{B}$ 's most valuable that $\boldsymbol{A}$ possesses) and adds it to a list. Each continues to add resources to their list until the list's value is at least the value of the device up for trade. Then, they split the difference of their lists.

Agent $\boldsymbol{A}$ technically places an order for the device: agent $\boldsymbol{B}$ still needs to produce it. $\boldsymbol{B}$ reserves the minutes required to produce it in the next day. If $\boldsymbol{B}$ doesn't already own a component for the device to be produced, $\boldsymbol{B}$ will attempt to buy it in subsequent trade rounds.

Finally, this phase ends with all agents determining if they will make devices for themselves. They follow similar logic as above-agents calculate a benefit and cost of production for every device they can produce. If the benefit outweighs the production cost, the agent will reserve the needed minutes and produce the device in the next day. 


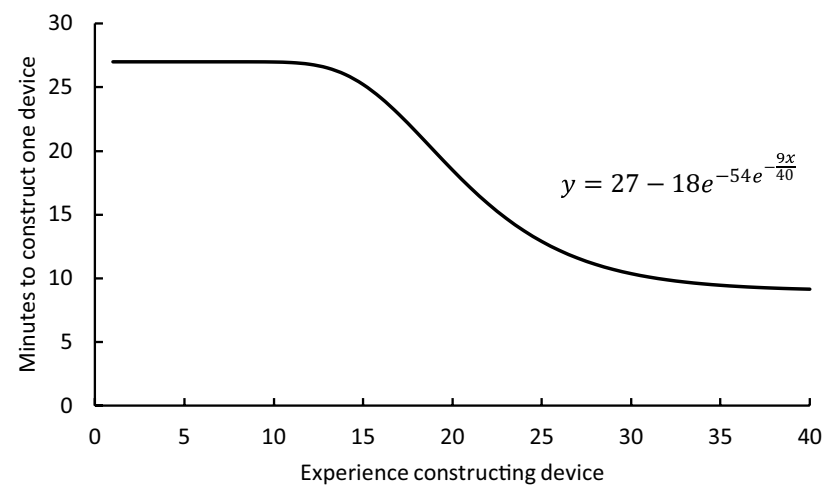

Fig. 10 Device effort curve

\section{Device Production}

Within the device production phase, agents build the devices on order from other customers or for themselves. The agents start building tier 1 devices and end with tier 4 devices so that lower tiers can be combined into higher tiers. For every device made, the agent subtracts the components from its holdings and reserves minutes to build it in the next day.

Devices take minutes to produce, but the amount varies depending on the device experience. Note that, each device has separate experience. Each time an agent makes a tier 1 device, the agent receives 1 experience for that device. Producing tier 2-4 devices generates 2,4 , and 8 experience, respectively. The required minutes vary based on Fig. 10 . To model technological learning-by-doing, the sigmoidshaped Device Effort Curve is produced using a generalized logistic (Gompertz) function, shown to the right of the curve in Fig. 9.

If an agent does not make a device during this phase, it will lose one experience for that device. So, agents lose proficiency at skills that are not actively used. If an agent has less than two experience for a device (newly invented devices, for example) but purchases it, the device experience will be set to two. This is a reverse engineering mechanism that gives a slight initial boost to agents that trade for new devices.

\section{Resource Consumption}

The final phase in each time-step is resource consumption. Resources are consumed to account for depreciation, decay, and to create biophysical requirements for the agents. In this paper, agents consume an average of $25 \%$ of each resource in their possession. Specifically, a resource unit is drawn from a binomial distribution with probability of consumption equal to 0.25 .
Devices also depreciate in this phase, regardless of utilization. Every device held by an agent loses $3 \mathrm{~min}$ of its lifetime.

\section{Results and Discussion}

A main simulation choice is the number of agents and resources. The results in this paper are based on 24 agents and 24 resources. These numbers are large enough that both aggregated wealth and technological interdependence change slowly and smoothly over time, but small enough for simulations to run in a reasonable amount of computational time. Note that, the model is robust to variations in these values; more details are in the appendices.

This model assumes that natural resources are unlimited to see how social and economic structures form without constraints. We can also inject a supply shock by suddenly removing a resource to study how SOCIETIES react. As a reminder, agents do not account for a potential supply shock or depletion of a resource during their economic activity.

\section{Technological Innovation with Unlimited Resources}

For the initial model runs, resources are unlimited in order to focus on technological innovation. We focus on five parameter variations-limiting the maximum device tier to $1,2,3$, or 4, and completely disabling devices. Figure 11 shows the mean agent utility for these runs. Because this is a stochastic model, each parameter set is run 30 times. $^{6}$

Here, the dark-colored lines show the average output for a max device tier, while the light-colored lines show the quartiles for tiers 2, 3, and 4. Note that, for tier 1 and no devices, the quartiles are omitted because the lines almost perfectly overlap the mean.

The society starts with no devices and over time increase utility through resource extraction aided by gaining experience and the efficiency gains from using devices. For the tier 1 limit, the agents discover and build devices up to time-step (day) 300. By day 300, they have discovered a device for every resource and reach the upper limit of technological development- there can be no more productivity gains which results in a per capita steady state. The same pattern holds for every additional device tier, although it takes slightly longer to reach saturation because agents can invent more complex devices.

\footnotetext{
6 We determined that 30 runs was an appropriate number through analysis provided in the "Appendix".
} 


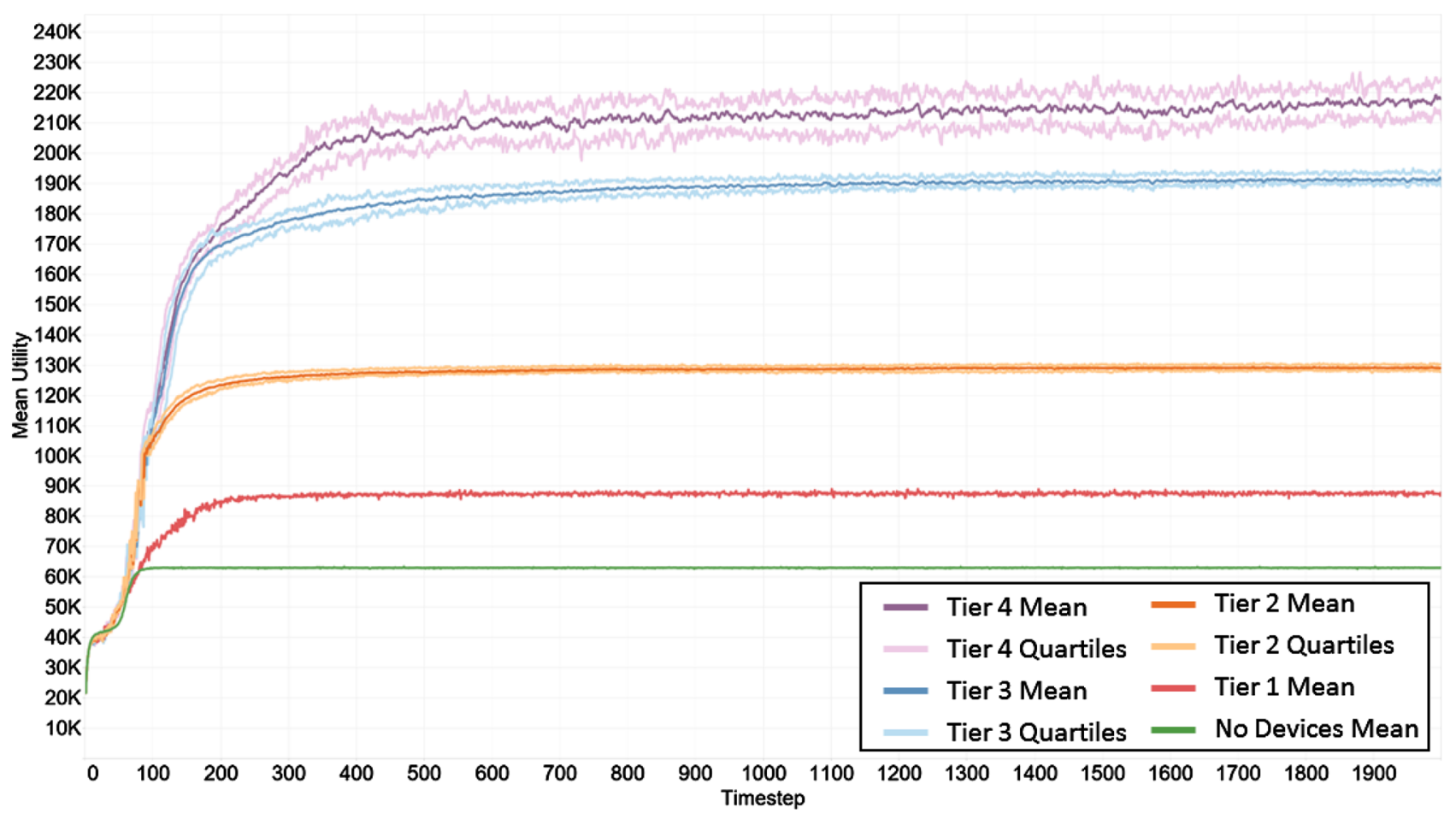

Fig. 11 Model output with unlimited resources

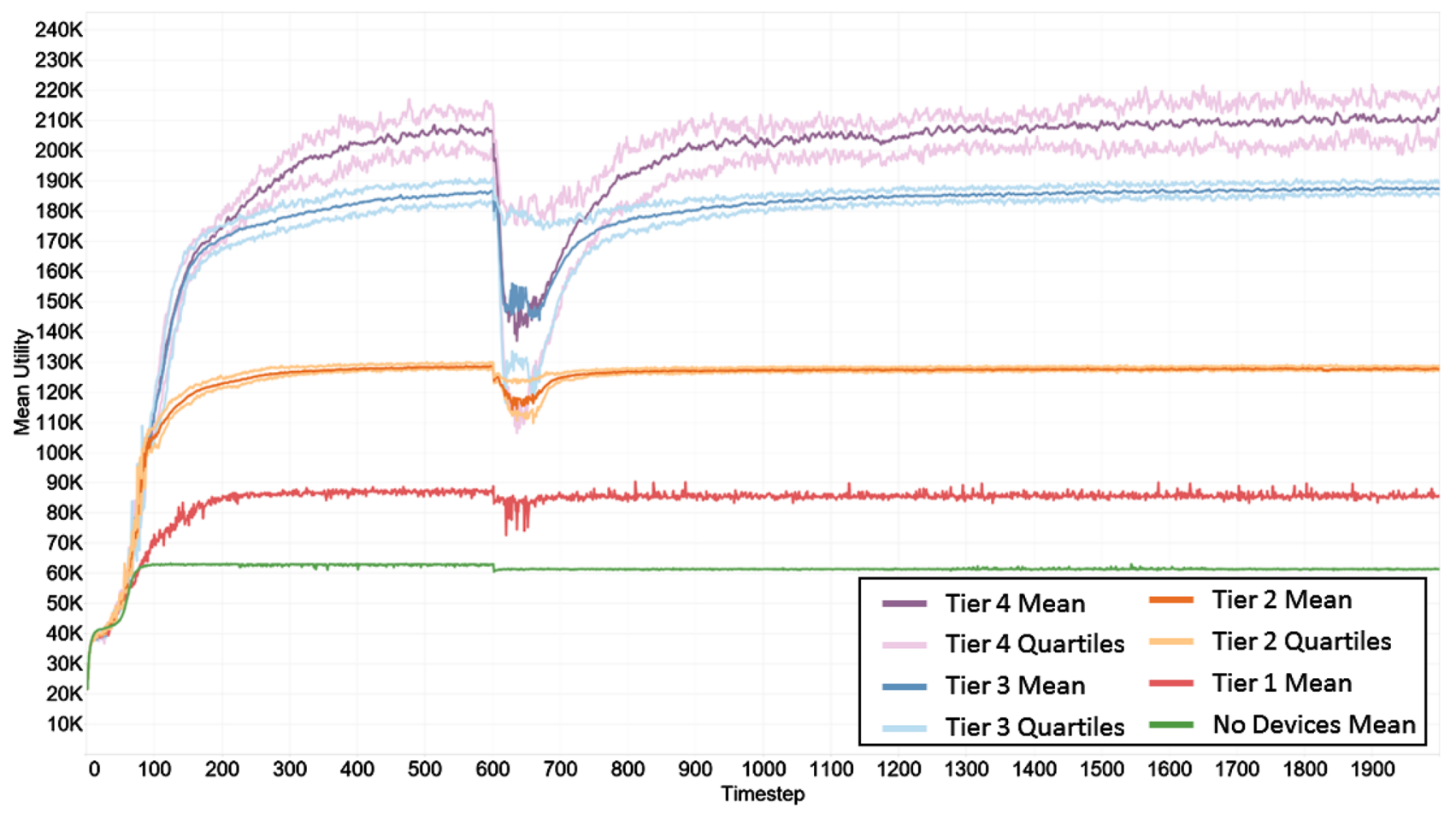

Fig. 12 Model output, collapse scenario 
Table 1 Collapse

characteristics

\begin{tabular}{lllllll}
\hline Device level & $\begin{array}{l}\text { Utility before } \\
\text { collapse } \\
\text { (units) }\end{array}$ & $\begin{array}{l}\text { Utility after } \\
\text { collapse } \\
\text { (units) }\end{array}$ & $\begin{array}{l}\text { Utility during } \\
\text { collapse (units) }\end{array}$ & $\begin{array}{l}\text { Collapse } \\
\text { severity } \\
(\%)\end{array}$ & $\begin{array}{l}\text { Time to initial } \\
\text { steady state } \\
\text { (days) }\end{array}$ & $\begin{array}{l}\text { Recov- } \\
\text { ery time } \\
\text { (days) }\end{array}$ \\
\hline Tier 1 & 88,000 & 85,000 & 79,500 & 9.7 & 300 & 100 \\
Tier 2 & 130,000 & 125,000 & 110,000 & 15.4 & 400 & 200 \\
Tier 3 & 190,000 & 185,000 & 142,000 & 25.3 & 500 & 600 \\
Tier 4 & 209,000 & 210,000 & 143,000 & 31.9 & 500 & 800 \\
\hline
\end{tabular}

Fig. 13 The effect of resource extraction on mean utility generation, with a resource removed at time-step 600 and Tier 4 devices available. The color shift occurs at time-step 600 and the green becomes more saturated towards the end of the simulation

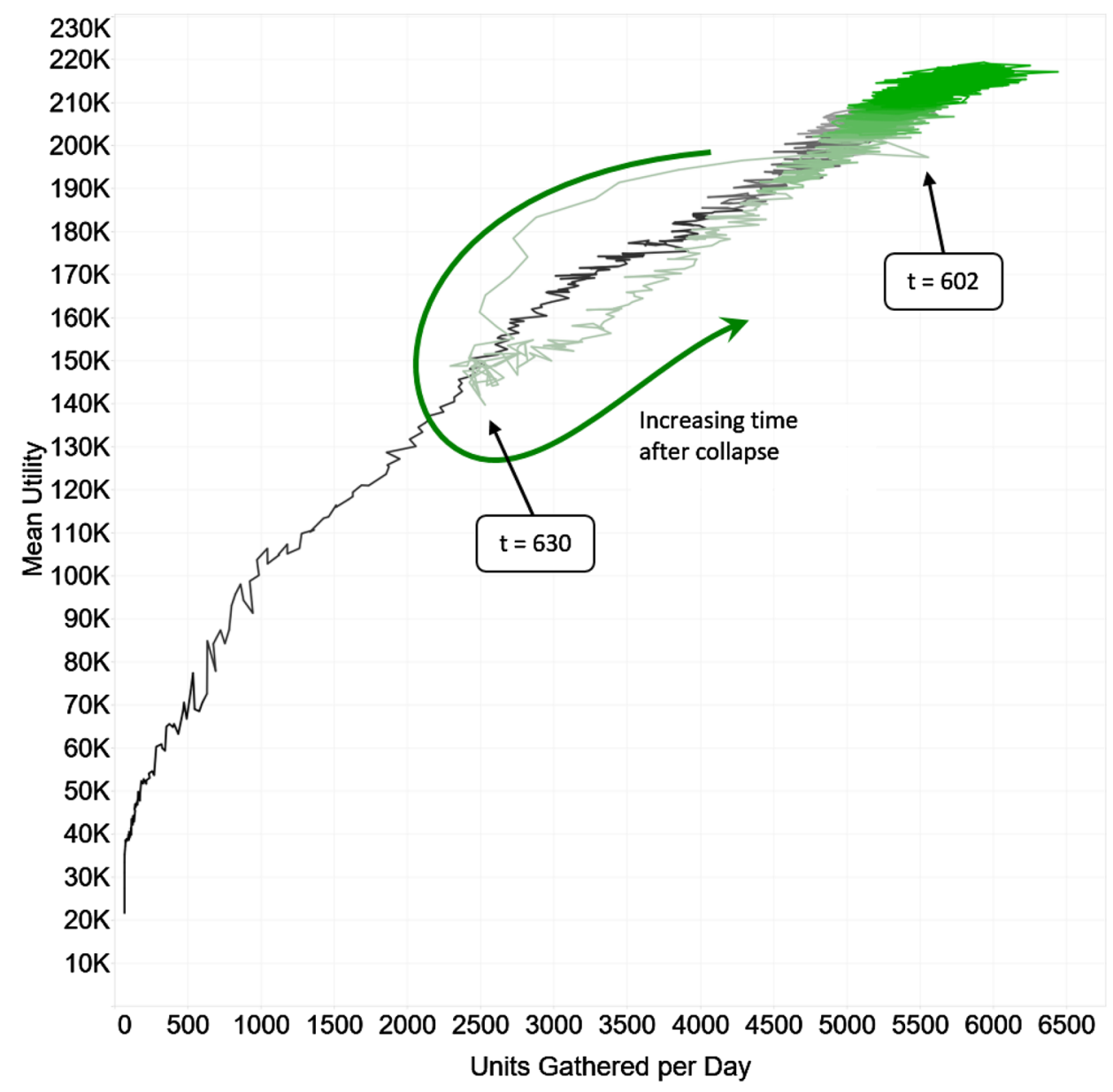

\section{Modeling Resource Supply Constraint}

In the next scenario, one resource is deleted from the environment at time-step 600. Agents can no longer extract the deleted resource. ${ }^{7}$ The average agent quickly loses a portion of its utility (see Fig. 12) as devices wear out and new

\footnotetext{
7 We modeled two variations of deleting a resource: deletion from only the environment, or global deletion including all agents' inventories of the resource. Both variations produce functionally identical results. This is because it only takes a few days to deplete resource reserves by building devices or through the resource consumption stage.
}

ones cannot be built using the old recipes. Agents work around the missing resource by reinventing devices, but the rate of utility growth is slower. They again reach a pseudo steady state (roughly time-step 1000 for tier 3 and 4), but the level is slightly lower than before because there is one less resource to draw utility from. Note that, lower tier runs face very little collapse while the higher tier runs face significant collapses. Exact numbers are provided in Table 1.

We quantify the collapse severity by comparing the lowest utility reached during collapse to the pre-collapse steady-state values. The basic tier 1 society experiences a small collapse of $9.7 \%$ and has a quick recovery time. As device tiers increase, the collapse severity increases 
to $31.9 \%$ for tier 4 . Both tier 3 and 4 societies experience recovery times longer than the initial time it took to build the economy. Tier 4 society initially took 500 time-steps to invent every device, but takes roughly 800 time-steps to reinvent all devices and reach a steady state after the resource supply shock.

In every collapse scenario involving devices, the collapse severity was larger than the individual cost-share of the lost resource. On average, a resource's cost-share is roughly $4.2 \%$ (each of the 24 resources are, on average, extracted evenly due to homogenous utility curves). Therefore, every resource within the SOCIETIES model has a greater impact within the economy than its cost-share would suggest.

\section{Comparing Mean Utility to Resources Gathered}

We can compare the agent utility to the number of resources gathered per time-step, seen in Fig. 13. These values differ because of the diminishing marginal utility of resource extraction. Agents must extract more and more of a resource to maintain the same rate of utility generation because they gain less utility for each additional resource unit.

Figure 13 shows the diminishing marginal utility through a decreasing slope. Note that, the line is colored green after a resource is removed at time-step 600. Right after time-step 600, agents can no longer produce devices with the removed resource. They also have not yet reinvented devices that were reliant on the removed resource. As a consequence, agents spend many more minutes each day extracting resources rather than building devices. This corresponds to an increased number of units gathered until the old devices begin to wear out (time-step 602). As their old devices wear out, the amount of units gathered each day significantly drops. The agents' mean utility does not change, however, until they start inventing and building new devices (corresponding to a drop in mean utility). They spend a few days building inventory, and then begin to proceed as normal at roughly time-step 630 . The new path follows the same initial trajectory, which indicates a similar technological development pathway to the original economic development.

\section{Sensitivity Analysis}

A major parameter is the number of different resources required to construct a tier 1 device. Because tier 1 devices are sub-components of all higher tier devices, varying the required number of resources has compound effects throughout all types of capital formation.

The default setting is four components per device. We ran the model with variations of $2,4,6$, and 8 components

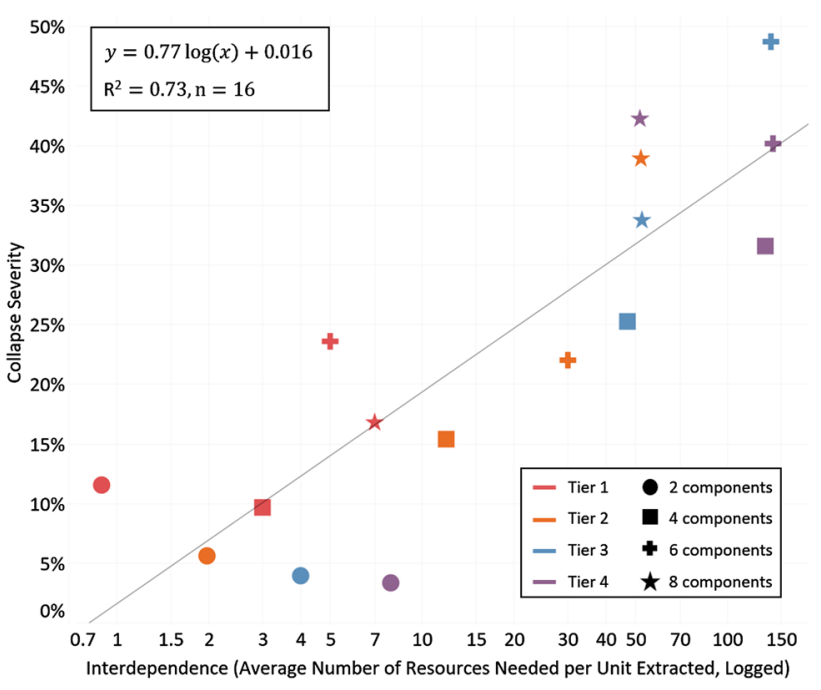

Fig. 14 Economic collapse severity as a function of interdependence. The trend line is calculated using all data points

Table 2 Technical collapse severity sensitivity analysis. Darkercolored cells indicate more severe collapse. Note that 2 device components is a lower limit of the model. (Color figure online)

\begin{tabular}{clrrr}
$\begin{array}{c}\text { Device } \\
\text { Components }\end{array}$ & \multicolumn{4}{c}{ Tier } \\
\hline 2 & $4.5 \%$ & $0.5 \%$ & $2.5 \%$ & $6.3 \%$ \\
\hline 4 & $4.0 \%$ & $10.0 \%$ & $31.1 \%$ & $55.0 \%$ \\
\hline 6 & $4.1 \%$ & $27.3 \%$ & $85.0 \%$ & $83.0 \%$ \\
\hline 8 & $4.6 \%$ & $73.1 \%$ & $70.9 \%$ & $70.9 \%$ \\
\hline
\end{tabular}

per device. We also placed limits on the highest device tier for a given parameter set, similar to the main analysis. Each set of parameters ran 30 times, resulting in Fig. 15.

As the number of device components increases, the agents require a larger supply chain and resource base to construct devices. Increasing the tier limit affects the complexity of devices. These parameters essentially control the level of resource-interdependence embedded within technology. Here, we define interdependence as the average number of resources required to extract one more unit of a resource. As this interdependence increases, there is a tendency to experience more resource criticality and collapse. Figure 14 shows the observed collapse severity for each parameter set. Here, collapse severity is calculated by comparing the mean utility before a collapse and at the minimum of the collapse, as shown in Table 1.

Within Fig. 14, data points gain edges as the number of device components increases. In general, there is a positive correlation between interdependence and collapse severity. Note that, the square series is the primary parameter set within this paper and follows a highly correlated trend. 
Fig. 15 Model parameter sweeps. The vertical axis represents number of sub-components per device. The horizontal axis represents the highest device tier available. The color shifts to red after a resource is depleted at time-step 600 . (Color figure online)

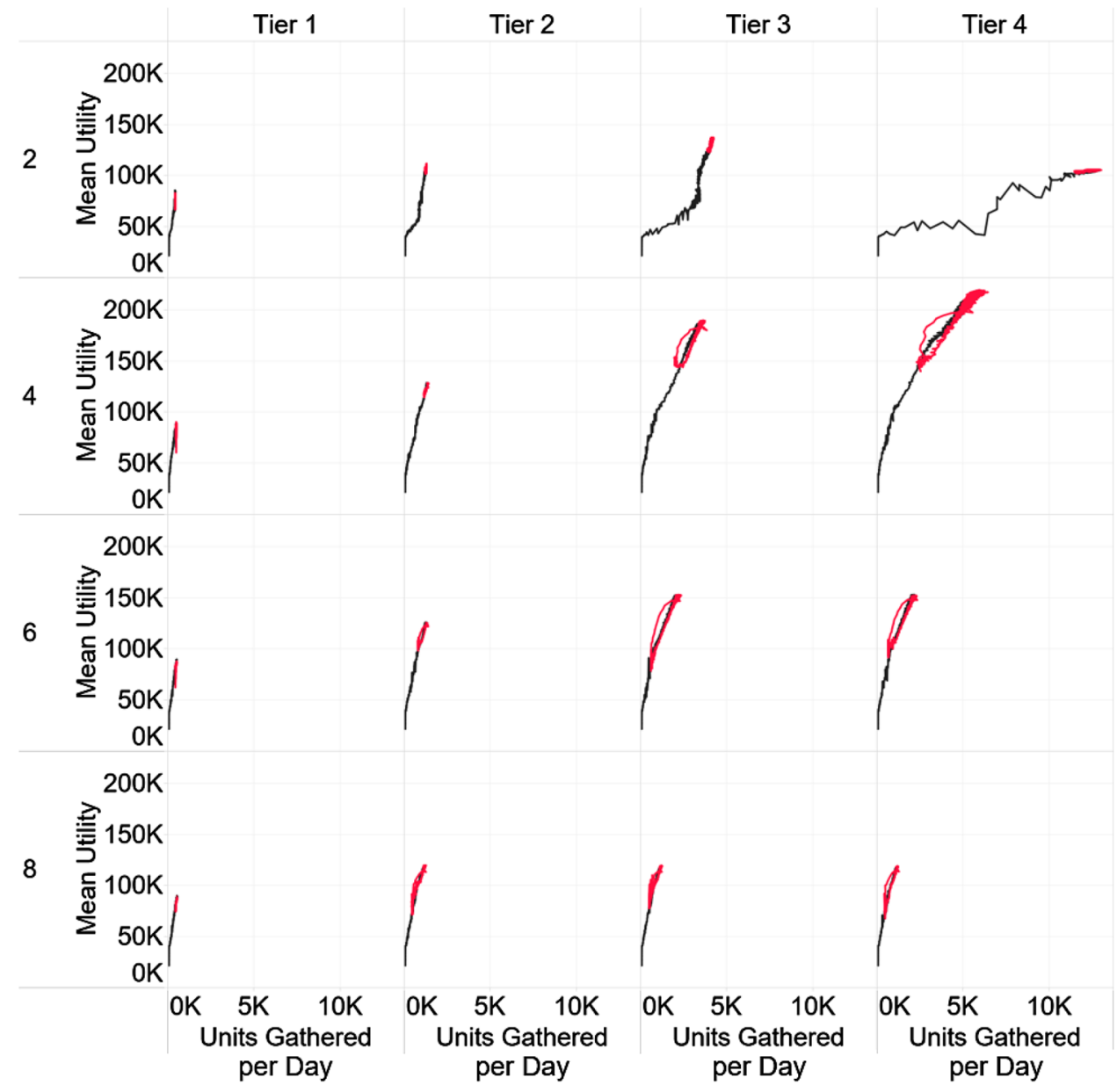

Other parameter sets tend to have underlying behavior that deviates from this trend. For example, the tier 2-4 star points all have roughly the same level of interdependence.

To help understand these behaviors, we look at the collapse through a different lens. Table 2 lists the collapse severity in terms of lost interdependence-the number of resources used to extract a resource. We term this a technical collapse because it is an indicator of agents shifting towards lower-tier devices rather than an indicator of dropping utility. By directly viewing the technical collapse, it is easier to decipher how agents interact with technology (though at the expense of understanding economic impacts).

Regardless of device components, Tier 1 societies experience similar technical collapse severities because their supply chains are all shallow with basic devices. There is not enough interdependence to drastically affect the economy. The collapse severity increases with device complexity, though eight device components plateaus at roughly $70 \%$. Because so many components are required for each subsequent tier, it is uneconomical to construct tier 3 and 4 devices with 8 components each-limiting the complexity. The agents simply stop building devices beyond tier 2 , which is why tier 2-4 star points have similar interdependence levels in Fig. 14. Nevertheless, more resource-interdependent agents tend to face larger collapses along with greater economic development.

To gain insight into economic development pathways, we return to comparing mean utility and resources gathered for all parameter sets (Fig. 15).

When limited to tier 1 or 2 devices, economic development is roughly the same regardless of the number of components per device. Development begins to vary by introducing tier 3 and tier 4 devices. The tier 4, 2 components case is abnormal behavior considered outside the limits of the model. As the number of components increases, the available minutes for resource extraction decreases because more lower-tier devices and more resources are needed to produce a device. The tier 4 , four components case is the default for our analysis because it reached the highest levels of mean utility and units gathered. This allows for better study of a resource depletion due to more pronounced negative effects. 


\section{Conclusion}

This paper presents an economic modeling framework that demonstrates ways that advanced economies can be susceptible to severe collapse and lengthy recovery scenarios, even in the presence of extraordinarily high levels of economic output. The industrial revolution produced great leaps in material well-being in large part through harnessing the power of fossil fuels and incorporating natural resources with highly specific properties into manufacturing processes. This extraordinary material wealth, however, has come with a hidden cost. The same technology and resource-dependence that produces high levels of output can also create latent vulnerabilities within the system (Graedel et al. 2015a, b; Chen and Graedel 2015). A seemingly small disruption in the complex network of resource and technological interdependencies can lead to an unexpected cascading collapse in productivity and severe drop in societal well-being. When hidden system vulnerabilities exist, historical patterns of smooth, exponential growth in economic output are not necessarily the best predictors of the future. Production may suffer a sudden collapse and lengthy recovery period unlike anything experienced before (Stern 1997).

As levels of resource criticality and technological interdependence have increased in recent decades, traditional macroeconomic models have begun to show signs of wear. Policy-makers and others have called for fresh thinking (Colander and Kupers 2014; Simpson 2013; Vriend 2002). Interest in and development of alternative macroeconomic models has increased. Several new approaches are currently being explored that examine different facets of the macroeconomy. One category of these new models explores how an economy might behave as a complex adaptive system. The economy is created "from the bottom up" as a network of interdependent economic agents (Colander and Kupers 2014; Epstein and Axtell 1996; Arthur 2015). Another category of approaches examines the dependence of the built economy on natural resources. These often extend traditional Solow growth-type models to include natural resources or energy in the pursuit of demonstrating biophysical constraints (Brock and Taylor 2010; Arbex and Perobelli 2010).

The approach taken in this paper models both of these important facets of the macroeconomy: technological growth as a complex adaptive system and binding biophysical constraints on macroeconomic growth. In SOCIETIES, heterogeneous economic agents interact with the natural environment and with each other to form trading networks, innovate, and build increasingly advanced technological devices. Levels of output from this simulated economy grow exponentially, ${ }^{8}$ producing trajectories of macroeconomic outcomes similar to those generated by traditional economic models and observed in historical time series. However, the underlying framework of SOCIETIES also allows an economy to suffer collapse and recovery scenarios when it encounters a binding biophysical constraint. This alternative framework demonstrates that potentially devastating macroeconomic outcomes are indeed possible when the simplifying assumptions used in traditional macroeconomic models are removed. These potential vulnerabilities are not taken seriously as real possibilities because the assumptions that undergird traditional economic models do not allow for them.

Collapse and recovery scenarios are explicitly ruled out in Solow growth models and other traditional modeling frameworks. These models assume and require that macroeconomic outcomes follow a smooth trajectory, modeled best by a twice differentiable function (Solow 2007). The seemingly innocuous assumption of smooth growth results from four underlying assumptions detailed in "Where are Resources in Macro-Economic Growth Models?" Assumption 1 is that substitutes for resources and technology exist—or will exist in a short enough time frame that transitions occur smoothly. This explicitly rules out resource criticality.

Assumption 2 is that cost-shares drive derivatives. That is, models use cost-shares of inputs to production to determine their relative impact on production, if their input levels were to change. The cost-shares of energy and natural resource inputs are relatively small compared to labor and capital cost-shares, which have remained virtually constant at 70 and $30 \%$ over time. Thus, modelers expect that production output levels will not be impacted by a natural resource supply shock. Graedel and others argue against this expectation-resource criticality and technological interdependence has likely de-coupled the importance of an input from its cost-share (Graedel et al. 2015a, b; Chen and Graedel 2015). A supply shock to a natural resource can have a disproportionate, cascading effect on production, despite its relatively small cost-share.

Assumption 3 is that economic agents act with perfect information and foresight. That is, agents are aware of potential supply shocks, understand the potential impact on production of a supply shock, and take all of this into account in pricing and technological decisions. Thus, it is assumed that the price of a critical, potentially constrained resource results from a perfectly competitive market and that the price will rise proportionately and just in time to

\footnotetext{
8 That is, until the model reaches its upper limit of productivity improvements (see "Technological Innovation with Unlimited Resources").
} 
signal development of a substitute before resource criticality would impact output. However, this assumption can be unrealistic because the behavior of a complex, interdependent economy may not be as predictable as traditional models suggest. Information needed to allocate resources efficiently or plan for capital investment may be unavailable or incorrect.

Lastly, Assumption 4 is that the economy consists of representative agents rather than interactions of a multitude of heterogeneous agents. Deep interdependencies that result from specialization accompanied by path-dependent trade networks cannot be captured in even the most advanced dynamic stochastic general equilibrium (representative agent) model (Del Negro 2013). The rich tapestry of economic behavior that leverages specialization and trade for economic growth is celebrated in the economics discipline and is assumed to be occurring in traditional economic models. But, this celebrated trade and innovation must occur in the background. It remains off-stage in traditional economic models for tractability. Trading relationships modeled in such simplified terms cannot capture increasing vulnerabilities to supply shocks.

The strength of the SOCIETIES agent-based model presented here is that it does not require any of these four problematic assumptions. First, it does not need to assume homogeneity in order to use representative agents (Assumption 4). Agent-based models can explicitly model the dynamic, interdependent networks that emerge as a result of specialization, trade, and technological innovation decisions of multitudes of heterogeneous agents. This allows for path-dependent, non-linear trajectories of macroeconomic outcomes that might occur in collapse and recovery scenarios.

Second, SOCIETIES does not have to assume perfect knowledge and foresight (Assumption 3). As agents interact, trajectories of macroeconomic outcomes emerge endogenously rather than as a result of predictable calculations. This allows supply shocks to be unexpected and for production to be hampered by over-investment in now defunct capital infrastructure that took place in previous time-steps.

Third, agent-based models in general can allow relationships between inputs and macroeconomic outcomes to emerge endogenously rather than resulting from a predefined functional form and estimated parameters. SOCIETIES' framework takes advantage of this and explicitly models how trade and technology drives derivatives rather than cost-shares (Assumption 2). SOCIETIES models the dynamic relationship between output and all inputs, including capital, labor, technology, and natural resources. Thus, the effect on output of a shock to the supply of one seemingly insignificant resource can be traced out over several simulated time-steps by the model.
Lastly, the design of SOCIETES allows for the possibility that substitutes for resources or technological devices may not be available in a short enough time frame to prevent collapse in the face of a supply shock (Assumption 1). This framework is designed to explicitly allow some resources and technology to have disproportionate impacts on production and demonstrate the potential for collapse and recovery scenarios in advanced economies.

The collapse and recovery scenarios examined in this paper demonstrate two important results for understanding the behavior of advanced economies.

First, resource criticality and economic collapse can occur even with generic, homogenous natural resources. ${ }^{9}$ In the simulated economies with high levels of technological interdependence, removing any resource led to a large decline in economic output. Our model's largest collapse severity was $31.9 \%$ despite an average resource cost-share of just 4.2\% ("Modeling Resource Supply Constraint"). Similarly, Cuba faced a GDP reduction of $35 \%$ after losing its oil imports, despite spending a relatively small amount on oil. ${ }^{10}$ Therefore, this paper reinforces the biophysical perspective that natural resources have a disproportionate impact on macroeconomic outcomes, not tied to their cost-share. Cuba's economy faced huge productivity losses because they lost portions of their energy supply, a requirement for most economic activity. Just as in our model, Cuba's GDP eventually started to recover as they implemented new policies and altered the structure of their economy. Agents in SOCIETIES needed to restructure their economy and redesign technology away from the removed resource. Qualitatively, the Cuba collapse and recovery in Fig. 1 is similar to our model's collapse and recovery in Fig. 12.

Second, the intensity of a potential economic collapse may be unexpected. As technological advancement leads to exponentially higher levels of observed economic output, it is also creating increasing levels of unobserved vulnerability. This idea parallels Graedel's comments on material use. As products become more optimized for their given task, each material "is carefully chosen to enable exquisite

\footnotetext{
${ }^{9}$ Every resource has the same initial properties, though they cannot be directly substituted in device recipes.

${ }^{10}$ Ideally, we could compare the total Cuban oil spending to our model's resource cost-share. However, there is poor or missing data availability for Cuban imports. Additionally, the USSR heavily subsidized Cuba which skew import and export prices (Purcell 1991). We know that Cuba imported roughly 10-12 million tonnes of oil equivalent (mtoe) in 1989, the start of their collapse (Purcell 1991). Cuba's GDP was 27 billion USD (nominal), and both the WTI and Brent spot price of oil was roughly $\$ 18$ per barrel (nominal). Assuming Cuba paid this spot price for its imports (a cost of 1.3 billion USD) and all energy imports were oil, their cost-share of oil would have been roughly $5 \%$.
} 
performance, precise physical and chemical properties essentially become requirements," leading to a varied mix of resources used to create a final product (Graedel et al. 2015). Intel, for example, increased the number of elements within computer chips from 12 in the 1980 s to roughly 60 by 2000 (21). As technological interdependence continues to increase, traditional models of macroeconomic behavior will increasingly miss the mark. Agent-based models and other approaches to understanding the behavior of a complex economy should continue to be validated against the empirical record.

\section{Model Assumptions and Limitations}

A drawback to agent-based models is that they require several assumptions, often of a different nature than traditional assumptions used in mainstream economic models. This section identifies several assumptions related to each of the elements of the model (agents, resources, trade, and technology) and discusses the impact of these assumptions on the results.

Two key economic assumptions undergird the model and create the conditions for collapse and recovery: (1) learning-by-doing (diminishing effort curves); and (2) diminishing marginal utility. Together, these two assumptions lead to specialization and trade, and increasing levels of technological interdependence. These assumptions are rarely disputed in the vast majority of economics literature, although a variety of functional forms to model them could be used. The general functional forms chosen for this paper are common to the mainstream literature. The simulation results are robust to a wide range of specific parameter values used in them. However, full parameter sweeps and exploration of other functional forms is planned for future work.

While traditional macroeconomic models may err on the side of assuming too much factor substitutability, this paper errs in the opposite direction. This model assumes that resources have no direct substitutes. Resource substitution abounds in reality, although there is debate on the degree of substitutability. Jewelry, for example, can be crafted out of many different metals that all use similar refining and manufacturing processes. However, cars cannot run on coala type of energy resource-without a significant redesign. SOCIETIES treats all devices more like the car than the jewelry; redesigns are always needed in the model. Thus, this model assumption biases the results toward greater collapse and recovery scenarios than would occur in reality.

SOCIETIES also assumes that there is no technological redundancy. But, redundancy is quite common for many technologies. Several alternative ways to produce electricity currently exist side-by-side in the economy. Within the model, only one device exists for each resource at each technology tier. That is, a device in SOCIETIES more closely represents an entire class of real devices (of the same complexity level) which all provide the same function, such as producing electricity. At this level of abstraction, the assumption is that everything within a class of devices is built from the same materials or componentsall electronics rely on silicon, for example. Adding technological redundancy and factor substitutability to the model might reduce or even eliminate collapse and recovery scenarios. We intend to explore this in future work.

The assumption that the resource supply shock is exogenous, instantaneous, and unforeseen, also biases the results toward greater collapse and recovery scenarios. In realworld economies, agents might take preventative measures to reduce or prevent collapse. However, the bias toward more severe collapse and recovery scenarios is offset by assumption of infinite resources for all but the constrained resource.

The assumptions regarding agent behavior also bias the results against severe collapse and recovery because they intentionally stack the deck against the formation of specialization, trade, and technological interdependence. For example, agents are endowed with equal access to resources and have the same level of bargaining skills and power.

Much of the ABM literature has focused on examining the macroeconomic effects that emerge from the interaction of agents that exhibit these more realistic micro-behaviors. The evidence suggests that incorporating these assumptions diminishes the resilience of the economy and increases vulnerability (Tesfatsion and Judd 2006; Epstein and Axtell 1996; Hamill and Gilbert 2016). Thus, the fact that the model on balance is biased against producing collapse and recovery scenarios means that the simulation results in this paper are likely to understate the potential collapse and recovery scenarios in the real economy.

\section{Future Work}

The purpose of this paper was to demonstrate the capacity of an agent-based model to shed light on the relationship between resource criticality and technological interdependence. Despite each of the limitations outlined in the previous section, we believe that SOCIETIES is on a promising path to model biophysical economics problems. Agentbased models provide a significant number of advantages over traditional economic approaches, and a good deal of future biophysical economics research lies in areas that traditional economic approaches cannot adequately capture. Agent-based computational economics in general, and SOCIETIES in particular, is more readily able to capture the complexity of our economic systems leading to insights regarding system behavior that has previously been inaccessible. 
Fig. 16 Determining the optimal number of model runs through bootstrapping. The vertical axis shows percentages. Note that the horizontal axis is not a continuous number line

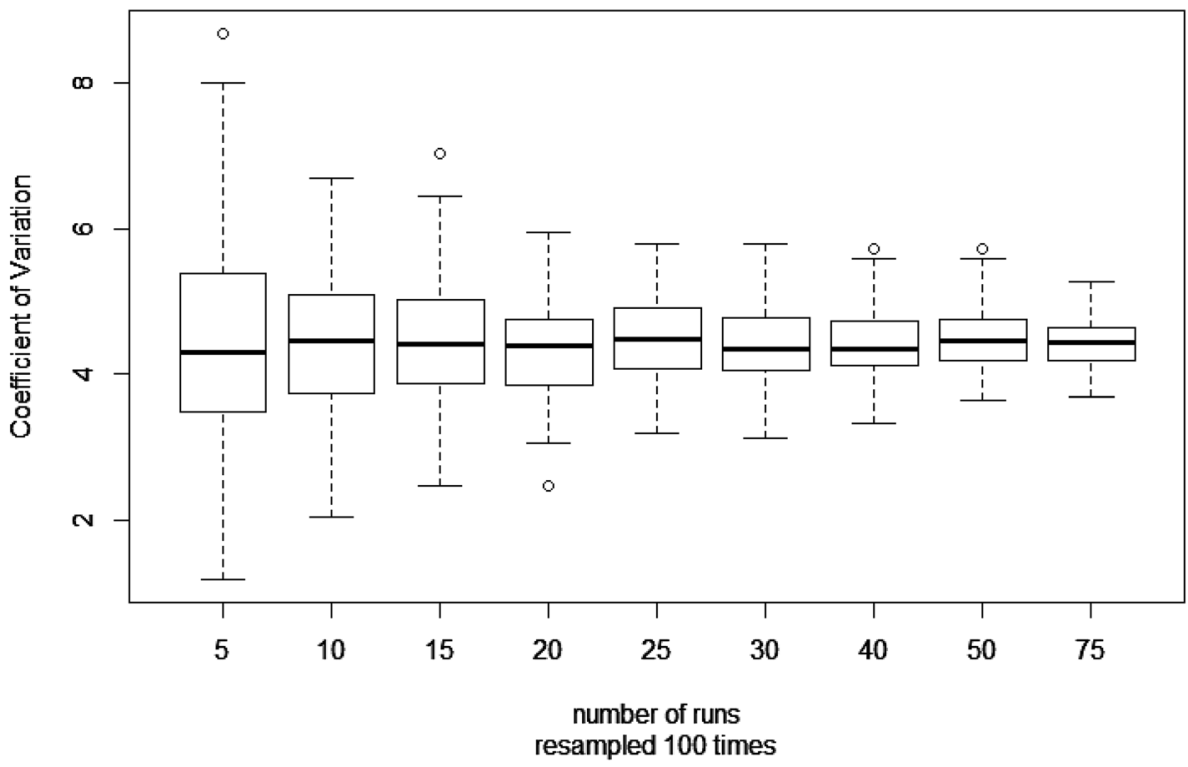

In addition to the future work testing the current model's limits outlined in the previous section, extensions to the model are planned. First, by creating specific resource types, SOCIETIES can examine how constrained supplies of energy, water, or materials, for example, might have different impacts on economic output. We can also create types of environmental pollution, stemming from the use of certain resources, which negatively impact the economy. Second, by introducing limited resources and providing agents some knowledge about resource stocks, SOCIETIES can examine various policy strategies for preventing or attenuating collapse due to resource depletion.

Finally, future plans also include using real-world data to validate the model. The current paper is purely a theoretical exercise, although it is encouraging that the simulated time series appear consistent with empirical time-series.

By incorporating these model extensions, we hope to build an empirically grounded agent-based model of society's economic and technical development that will help inform energy, economic, and environmental policy decisions.

Acknowledgements Portions of this research were conducted with funding from the U.S. Department of Education Graduate Assistance in Areas of National Need (GAANN) PR/Award No. P200A150310.

\section{Compliance with Ethical Standards}

Conflict of interest The authors declare that they have no conflict of interest.

Open Access This article is distributed under the terms of the Creative Commons Attribution 4.0 International License (http:// creativecommons.org/licenses/by/4.0/), which permits unrestricted use, distribution, and reproduction in any medium, provided you give appropriate credit to the original author(s) and the source, provide a link to the Creative Commons license, and indicate if changes were made.

\section{Appendix}

\section{Optimal Number of Model Runs}

Because SOCIETIES is a stochastic model, it is important to determine how many model runs provide an accurate representation of the probability space. There is a tradeoff between this accuracy and required computing time. SOCIETIES requires a nontrivial amount of computing time, so determining the optimal number of runs was a worthwhile exercise.

We followed Lee et al.'s approach towards determining the optimal number of runs for the main analysis of SOCIETIES (Lee et al. 2015). Because the tier 4, 4 components case saw the most variation (see "Results and Discussion"), we ran that case 100 times. The steady-state utility values (see Table 1) were determined for each run in order to create a population for a bootstrap analysis. Sets of $5,10,15$, etc., were sampled 100 times each. A coefficient of variation was generated for each set, and the distribution of all 100 coefficient of variations is shown in Fig. 16.

The variation between sets decreases as the set size increases. However, increasing the set size has a diminishing payoff. Past a set of 30 runs, there is little reduction in sample variation. Therefore, the default number of runs was chosen to be 30 in order to balance capturing model stochasticity and required computational resources. 
Fig. 17 Mean Utility for collapse scenarios as a function of number of agents and resources. The black line represents the average of 30 runs while the gray lines represent quartiles. These runs have the maximum device tier set to four and components per device set to 6

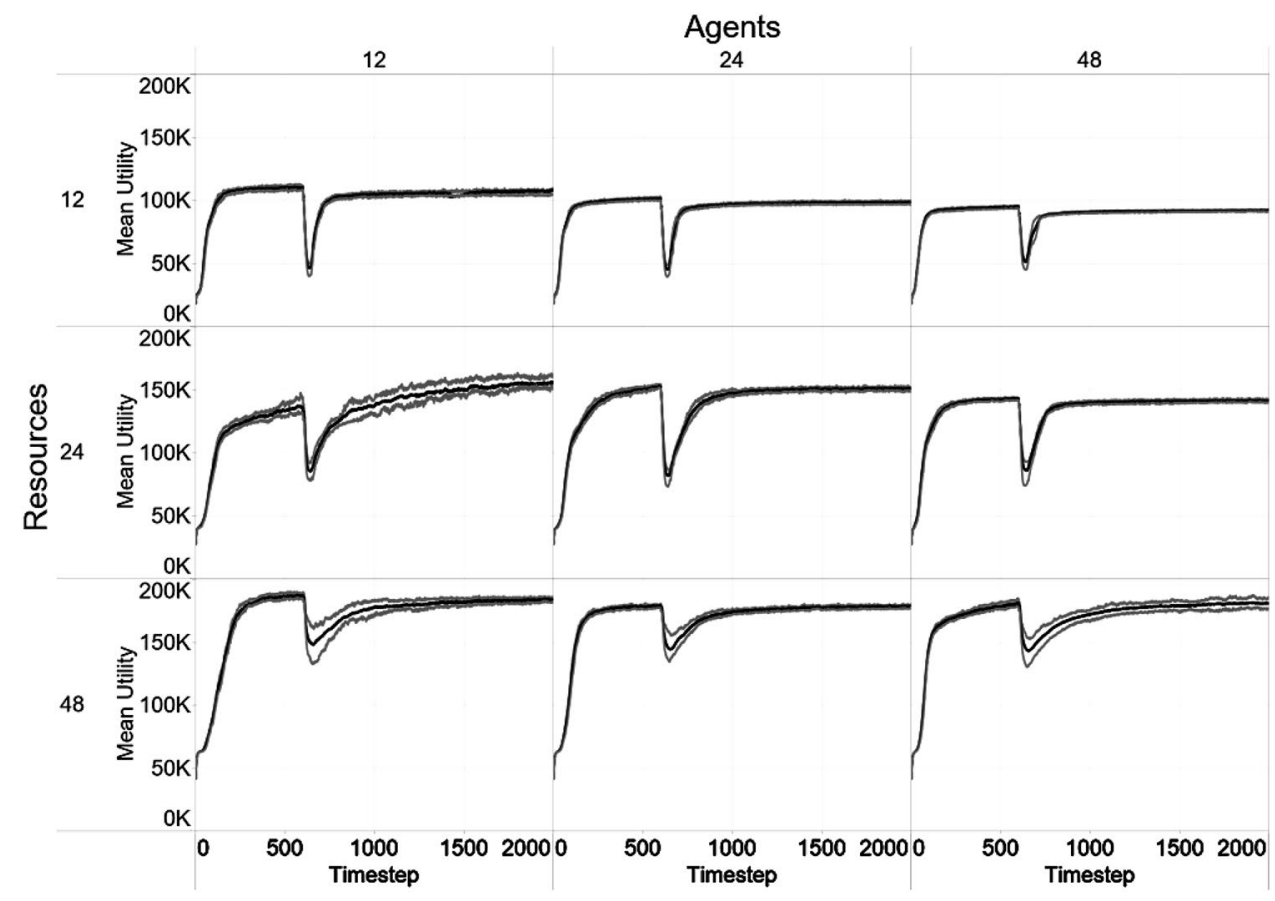

\section{Number of Agent and Resource Variations}

Two key parameter choices for SOCIETIES are the number of agents and number of resources. The number of agents should fulfill these objectives:

1. There ought to be enough agents to produce relatively smooth model outputs. Too few agents lead to large day-to-day variations in outputs such as mean agent utility or units gathered. If all agents decide to build devices for their entire day, the "units gathered," and other indicators, would go to zero. Increasing the number of agents reduces the probability of this happening.

2. Too many agents would take too much computing time, a relatively small number is computationally efficient.

3. An even number means that pairing up to trade would work nicely.

Numbers within the range of roughly $10-50$ would work well; we chose 24 for the main analysis. While it is somewhat arbitrary, 24 is easily divisible - it is easy to do diagnostic runs with $1 / 2,1 / 3,1 / 4$, or $1 / 6$ the number of agents.

Regarding resources, there ought to be enough for distinct recipes of high-tier devices. Looking at Fig. 8 (the example recipe tree), if there are too few resources, recipes for devices might begin to significantly overlap. While less than 24 resources would still work, 24 provides a good amount of recipe variability. Additionally, high-tier devices should be dependent on nearly all resources in order to appropriately model the interdependencies of advanced technology; too many resources would undermine this desired effect.

We varied the number of agents and resources to determine how influential the choices were on model results; this is shown in Fig. 17.

The results are similar across parameter sets, although the collapse tends to be slightly less severe with a large number of resources. In these scenarios, agents have too many resource options to extract or use in devices. They do not specialize as quickly, reach a higher utility (due to more high-utility resource options), and face a smaller collapse because the importance of the removed resource is diluted-a tier 4 device might not be dependent on every resource. So, despite increased computational time, adding more resources does not provide more information about tracing interdependencies throughout the economy.

Similarly, adding more agents than resources results in unnecessary redundancies. In these cases, each resource may have many agents specializing in its extraction. Agents begin to lose their heterogeneity, and modeling two nearly identical agents adds computational time without adding information relevant to the study of technological interconnectedness. Therefore, we chose to model 24 agents and 24 resources, giving each agent an opportunity to uniquely specialize in a resource. 


\section{References}

Andersen ES (1996) The evolution of economic complexity: a division-of-coordination-of-labor approach. University of Michigan Press, Ann Arbor

Anderson PW, Arrow K (1988) The economy as an evolving complex system. Westview Press, Colorado

Arbex M, Perobelli FS (2010) Solow meets Leontief: economic growth and energy consumption. Energy Econ 32(1):43-53

Arthur WB (1999) Complexity and the economy. Science 284(5411):107-109

Arthur WB (2015) Complexity and the economy. Oxford University Press, Oxford

Arthur WB, Durlauf SN, Lane D (eds) (1997) The economy as an evolving complex system II. Westview Press, Reading

Ayres RU, Warr B (2005) Accounting for growth: the role of physical work. Struct Change Econ Dyn 16(2):181-209

Ayres RU, J. C. J. M. van den Bergh, Lindenberger D, Warr B (2013) The underestimated contribution of energy to economic growth. Struct Change Econ Dyn 27:79-88

Balint T, Lamperti F, Mandel A, Napoletano M, Roventini A, Sapio A (2017) Complexity and the economics of climate change: a survey and a look forward. Ecol Econ

Brock WA, Taylor MS (2005) Chapter 28-economic growth and the environment: a review of theory and empirics. In: Aghion P, Durlauf SN (eds) Handbook of economic growth, vol 1, Part B. Elsevier, Amsterdam, pp 1749-1821

Brock WA, Taylor MS (2010) The green solow model. J Econ Growth 15(2):127-153

Chen W-Q, Graedel TE (2015) In-use product stocks link manufactured capital to natural capital. Proc Natl Acad Sci 112(20):6265-6270

Claessens S, Dell'Ariccia G, Igan D, Laeven L (2010) Cross-country experiences and policy implications from the global financial crisis. Econ Policy 25(62):267-293

Colander D, Kupers R (2014) Complexity and the art of public policy: solving society's problems from the bottom up. Princeton University Press, Princeton, NJ

Cuba GDP growth (annual \%) I Data, World Bank. [Online]. http://data.worldbank.org/indicator/NY.GDP.MKTP. KD.ZG?locations=CU. Accessed 13 Sept 2016

Cuba I Data, The World Bank [Online]. http://data.worldbank.org/ country/Cuba. Accessed 18 Apr 2017

Daly HE (2005) Economics in a full world. Sci Am 293(3):100-107

Del Negro M et al (2013) The FRBNY DSGE Model. FRB N. Y. Staff Rep no. 647

Durlauf SN (2012) Complexity, economics, and public policy. Polit Philos Econ 11(1):45-75

Economics focus: Agents of change, The Economist, 22-Jul-2010

Epstein JM, Axtell RL (1996) Growing artificial societies: social science from the bottom up, 1st edn. The MIT Press, Cambridge

Europe Brent Spot Price FOB (Dollars per Barrel) [Online]. https://www.eia.gov/dnav/pet/hist/LeafHandler. ashx? $=$ PET\&s=RBRTE\&f=D. Accessed 18 Apr 2017

Friedrichs J (2010) Global energy crunch: how different parts of the world would react to a peak oil scenario. Energy Policy 38(8):4562-4569

Graedel TE, Harper EM, Nassar NT, Nuss P, Reck BK (2015a) Criticality of metals and metalloids. Proc Natl Acad Sci 112(14):4257-4262

Graedel TE, Harper EM, Nassar NT, Reck BK (2015b) On the materials basis of modern society. Proc Natl Acad Sci 112(20):6295-6300

Gullickson W, Harper MJ (1987) Multifactor Productivity in U.S. Manufacturing, 1949-83. Mon Labor Rev 110:18
Hall C, Lindenberger D, Kümmel R, Kroeger T, Eichhorn W (2001) The need to reintegrate the natural sciences with economics: neoclassical economics, the dominant form of economics today, has at least three fundamental flaws from the perspective of the natural sciences, but it is possible to develop a different, biophysical basis for economics that can serve as a supplement to, or a replacement for, neoclassical economics. Bioscience 51(8):663-673

Hamill L, Gilbert N (2016) Agent-based modelling in economics, Chichester, UK, 1st edn. Wiley, Hoboken

Hartwick JM (1977) Intergenerational equity and the investing of rents from exhaustible resources. Am Econ Rev 67(5):972-974

Hartwick JM (1978) Substitution among exhaustible resources and intergenerational equity. Rev Econ Stud 45(2):347-354

Heun M, Santos J, Brockway P, Pruim R, Domingos T, Sakai M (2017) From theory to econometrics to energy policy: cautionary tales for policymaking using aggregate production functions. Energies 10(2):203

Hirsch RL (2005) The inevitable peaking of world oil production. Atl Counc US XVI(3):1-10

Hoel M, Kverndokk S (1996) Depletion of fossil fuels and the impacts of global warming. Resour Energy Econ 18(2):115-136

Holland JH, Miller JH (1991) Artificial adaptive agents in economic theory. Am Econ Rev 81(2):365-370

Hotelling H (1931) The economics of exhaustible resources. J Polit Econ 39(2):137-175

Kirman (2016) Complexity and economic policy: a paradigm shift or a change in perspective? a review essay on david colander and roland Kupers's complexity and the art of public policy ${ }^{\dagger}$. J Econ Lit 54(2):534-572

Kümmel R, Strassl W, Gossner A, Eichhorn W (1985) Technical progress and energy dependent production functions. Z Für Natl $\mathrm{J}$ Econ 45(3):285-311

Lee J-S et al (2015) The complexities of agent-based modeling output analysis. J Artif Soc Soc Simul 18(4):4

Meadows DH, Randers J, Meadows DL (2004) Limits to growth: the 30-year update, 3 edn. Chelsea Green Publishing, White River Junction, $\mathrm{Vt}$

Minerals, Critical Minerals, and the U.S. Economy (2008): Division on Earth and Life Studies [Online]. http://dels.nas.edu/Report/ Minerals-Critical-Minerals/12034. Accessed 13 Sept 2016

New model army; Economics after the crisis, The Economist, vol. 406, no. 8819, p. 75, 19-Jan-2013

Nordhaus WD (1979) Efficient use of energy resources. Yale Univ Pr, New Haven

Nordhaus WD (1993) Optimal greenhouse-gas reductions and tax policy in the 'DICE' model. Am Econ Rev 83(2):313-317

Norgaard RB (1990) Economic indicators of resource scarcity: a critical essay. J Environ Econ Manag 19(1):19-25

Pan H, Köhler J (2007) Technological change in energy systems: learning curves, logistic curves and input-output coefficients. Ecol Econ 63(4):749-758

Piercy E, Granger R, Goodier C (2010) Planning for peak oil: learning from Cuba's 'special period'. Proc Inst Civ Eng-Urban Des Plan 163(4):169-176

Purcell SK (1991) Collapsing Cuba. Foreign Aff 71(1):130-145

Simpson D (2013) The rediscovery of classical economics: adaptation, complexity and growth. Cheltenham, UK. Edward Elgar Pub, Northampton, MA

Smil V (2013) Making the modern world: materials and dematerialization, 1 edn. Wiley, Chichester, West Sussex, United Kingdom

Smulders S, Toman M, Withagen C (2014) Growth theory and 'green growth. Oxf Rev Econ Policy 30(3):423-446

Solow RM (2007) The last 50 years in growth theory and the next 10. Oxf Rev Econ Policy 23(1):3-14 
Squazzoni F (2010) The impact of agent-based models in the social sciences after 15 years of incursions. Hist Econ Ideas 18(2):197-233

Stern DI (1997) Limits to substitution and irreversibility in production and consumption: a neoclassical interpretation of ecological economics. Ecol Econ 21(3):197-215

Tainter J (1990) The collapse of complex societies, Reprint edition. Cambridge University Press, Cambridge
Tainter JA (2006) Archaeology of overshoot and collapse. Annu Rev Anthropol 35:59-74

Tesfatsion L, Judd KL (2006) Handbook of computational economics: agent-based computational economics. Elsevier, Amsterdam Vriend NJ (2002) Was Hayek an ace? South Econ J 68(4):811-840 